\title{
Multiple Output Inductive Charger for Electric Vehicles
}

\author{
Van-Binh Vu, Student Member, IEEE, Van-Tung Phan, Senior Member, IEEE, Mohamed Dahidah, Senior
}

Member, IEEE and Volker Pickert, Member, IEEE.

\begin{abstract}
Multiple output chargers have widely been adopted in various electronic devices due to their benefit concerning cost, power density, and space for installation. On the contrary, Inductive Power Transfer (IPT) has been applied increasingly in electric vehicles (EV) since it is safer and more convenient as compared to conductive chargers. However, researches on multiple output chargers using IPT system for EV charging applications are rarely presented. This paper proposes a new concept of a multiple output IPT charger, which can charge several output batteries independently and simultaneously by adopting only one full bridge inverter at the primary side combining with multiple transmitters. Two possible IPT-coil structures are analyzed, and the minimum distance between each channel's coils is determined to neglect the cross-coupling between them. Two options are proposed to attain Zero Phase Angle (ZPA) condition for primary inverter of the proposed system. First option is to operate the compensation tanks of every output channel at exact ZPA frequencies. The other option is to let one channel working in inductive region of its input impedance and other channel working in capacitive region. By adopting an appropriate design, the reactive powers of these tanks can be nearly cancelled each other and the phase of inverter current can be nearly in-phase with the input voltage as a result. Two proposed options are compared to give recommendation whether option 1 or 2 should be selected according to various of application's requirements. To simplify control complexity, IPT output current sources topologies are selected, compared and analyzed to construct the proposed multiple output system in both above options. Double-sided LCC and Series-Parallel (SP) topologies are adopted to demonstrate the proposed idea for Option 1 and 2 , respectively. In order to verify feasibility and validity of the proposed method, experimental results of two output channels with the total output power of $1.5 \mathrm{~kW}$ are provided. Experimental results indicate that the $\mathrm{ZPA}$ is achieved for primary inverter with both of two above options even under the different load conditions. Some comparisons between the conventional and the proposed IPT charging structure in terms of cost, reliability and complexity are included in discussion session.
\end{abstract}

Index Terms - Inductive power transfer; multiple output charger; IPT compensation topologies, wireless EV charging.

\section{INTRODUCTION}

Nowadays, plug-in charging is the most popular method to charge for Electric Vehicle (EV) or Hybrid Electric Vehicle (HEV) [1]. However, plug-in EV charging exists several drawbacks such as potential hazards and electric shock for users when handling the high power plug along with inconvenience under adverse weather conditions. In order to overcome the charging troublesome of plug-in EV charging, inductive power transfer (IPT) technology is started to research and apply to EV battery charging [2], [3]. In this technology, there is always an isolation between the transmitter coil and receiver coil and then the energy is transferred wirelessly from primary source side to secondary load side by using time-varying magnetic fields. The inductive charging system is normally suffered from low coupling coefficient due to a large air-gap or misalignment between transmitter and receiver coil. It results in an increase of reactive power and reduction of efficiency and power capability. To solve these problems, the compensation tanks are added to both sides of the system to resonating at the operating frequency [4]. The primary and secondary compensation circuits are both resonating at the operating frequency. Proper compensation design is required to make the input impedance resistive (equivalent to ZPA condition) so that component volt-ampere ratings are minimized and the reactive power stress is eliminated on the inverter circuit. There are four basic compensation topologies including Series-Series (SS), Series-Parallel (SP), Parallel-Series (PS) and Parallel-Parallel (PP), where the resonant capacitors are added to primary and secondary sides in series or parallel with wireless coil [4], [5]. To simplify the control of output voltage and improve the performance of IPT systems, higher order compensation topologies are investigated where more than a single capacitor are added to both sides of the IPT circuit [6-10]. In [6], [7] LCL compensation topology is developed by adding a LC tank between the primary full bridge inverter and followed by the parallel transmitter. LCL topology can operate as a current source at the fixed resonant frequency. However, the LCL topology requires bulky additional inductors on one side or both sides. In order to reduce the size and cost of the additional inductors, LCC compensation topology is suggested by employing a capacitor into LCL compensation tank in one side or both sides, which are connected in series with the coils [9], [10] Inductance values of additional inductors in LCC topology can be reduced to be significantly smaller than those of coils. The double-sided LCC topology has at least two ZPA frequencies for both current and voltage source output, which is very suitable for lithium battery charging [24-25].

Alongside compensation topologies, design and optimization of charging pad are also investigated to improve the coupling coefficient, extend the transfer distance and minimize electromagnetic field exposing to pedestrians. A charging pad normally consists of copper wire, ferrite sheets, and aluminum shields. The coupling coefficient varies significantly depending on different pad's geometries and configurations. There are two main types of charging pad as the double-sided and singled-side pad according to the magnetic flux distribution area [11]. The doubled-sided pad generates flux paths on both sides of the pad [12]. It results in the high stray field and the high eddy current loss in the aluminum shielding which is placed on the pad. To overcome the negative effects of the doubled-sided pad type, the singled-sided pads are proposed in [11], [13], and [14]. In this kind of system, the main flux path flows through magnetic sheets installed under the winding, and the flux mainly exists in the space between primary and secondary pad. The optimization of designing different types of single-sided pad with general purposes of improving coupling coefficient, a 
better misalignment tolerant and achieving low electromagnetic field exposing to pedestrians. Other approaches to improve the effectiveness in coupling coefficient and extend energy transfer distances are to adopt intermediate coils into the transmitter or receiver pads [1517]. The principle behind this improvement is that intermediate coils and associated resonant capacitors help to boost the apparent coupling coefficient in the system at the operating frequency while keeping the same coupling coefficient between transmitter and receiver coils. However, design guidance in this kind of systems is normally more complex than conventional two-coil IPT system.

On the other hand, multiple output charger (MOC) method is widely applied in various applications such as portable electronics devices, household equipment, and telecommunication [18]-[22]. A MOC system can provide several charging outputs from a (an) DC or AC input voltage source. Each battery of the output device is connected to the output port of the MOC system and is charged independently at the same time. Various DC/DC converter topologies are adopted in a MOC system [18-21]. There are several benefits of MOCs system such as reducing the cost, shortening the total charging time and space for installation due to using only one converter. However, MOC is commonly suffered from cross-regulation problem, in which the variation in voltage or power from one output channel affects the stability of the others. As a result, it requires complex circuits and control techniques to regulate the outputs independently and accurately [20], [22].

Plug-in electric vehicles and hybrid-electric vehicles typically consist of an on-board-charger (OBC) module as presented in [23]. The OBC module is commonly a two-stage power converter including a front-end ac/dc converter and an isolated dc/dc converter which converts from ac grid voltage into the required battery dc voltage. Differentiating from plug-in charger, front-end ac/dc converter, primary inverter and compensation tanks of $\mathrm{dc} / \mathrm{dc}$ converter have to be installed off-board of EV for inductive charging. Using conventional structure of plug-in charger for IPT charging station increases the installed area and costs because of using more inverter, front-end ac/dc circuits and associated gate drivers. Moreover, all transmitters are not always activated together at the same time, and then the presence of all associated inverters is not always necessary. Therefore, this paper proposes new approach to implement a multiple output IPT system for EV battery charging application as depicted in Fig. 1, which can charge for several output batteries independently and simultaneously from a single input source by adopting only one primary inverter. Differentiating from conventional multiple IPT system for low power applications [33-34], where a large transmitter are adopted to power up for multiple receivers. For high power applications, however, the conventional concept has drawbacks by generating high stray field and high losses in the transmitter's areas where no receiver covers up. This would degrade overall efficiency and be a serious problem for pedestrians because of high stray field level. In the proposed concept, we adopted multiple transmitters powered from a single inverter and each transmitter's current is easily either turned ON or OFF by using contactor. Therefore, stray field and losses are significantly reduced. The outputs of proposed system are all free from cross-regulation problem because of using different separated IPT coils for each channel. To implement the proposed system, two potential candidates of IPT coil structures are compared, and then the more suitable one is selected. The minimum distance between different channel's coils is chosen to cancel the cross-coupling problem between them. These contents with the concept of proposed system are mentioned in Section II. Section III proposes and compares two possible options to operating the proposed multiple output system with the intention of achieving ZPA condition for primary inverter of the proposed multiple system. One operating option is to design resonant component of each channel at its ZPA frequency. These ZPA frequencies are identical for all output channel and equal to the switching frequency of inverter as well. Some analyses and comparisons between different output load-independent current topologies are conducted to select the most suitable topology. The other option attains nearly ZPA condition based on the interaction between different compensation tanks in whole system. It is based on the fact that there are more than one resonant frequency in every IPT compensation circuits [24-27]. These resonant frequencies can be classified as resistive (ZPA), inductive or capacitive points depending on the phase of primary input impedance. In this paper, the analysis of two output channels with SP topology is conducted to illustrate in which one channel operating at inductive region of SP's input impedance and the other channel operating at capacitive region. It results in a cancellation of phase between two channel's currents and making the total input current is in-phase with input voltage. The phase-shift $\varphi$ between total input current and voltage are derived in which $\varphi$ depends on resonant component values and loads of both channels. To minimize $\varphi$, resonant components are selected suitably according to a specific range of load. The paper also points out how load variation affect to ZPA of inverter for each option. It is also noted that all previous papers working on ZPA achievement in IPT system are for single output channel only. The proposed second option is unique for multiple system as the above cancellation cannot be realized by conventional IPT charging structure. Consequently, the proposed multiple system is able to offer more options to realize ZPA operation for primary inverter. In both methods, load-independent output is selected to simplify the control of output voltage or current. With various of applications and different requirements, two possible options are compared to select the suitable one. Some verified simulation results are included in Section III to validate the proposed idea and design. In order to stable output power of each channel under the dynamic condition such as load or coupling coefficient variation, the closed-loop control and associated secondary side buck-boost converter are implemented. Section IV presents the experiment results where a prototype of $1.5 \mathrm{~kW}$ multiple output IPT charger including two output channels is built up and tested to verify the validity of the proposed method. Double-sided LCC and SP topologies are selected for evaluating Option 1 and 2, respectively. Different load conditions of two channels are carried on including the dynamic operation. Finally, some conclusions are drawn in Section $\mathrm{V}$, which contains comparisons between two above proposed options for multiple IPT system, as well as between the proposed system and the conventional IPT charging structure. 


\section{The Proposed Multiple OUtPUt IPT CHARGER}

\section{A. IPT coil structures selection}

Simulation models in Fig. 2 illustrate two possible IPT coil configurations of the proposed multiple output system. It is firstly assumed that the system is designed for two output batteries. Therefore, two circular receiver coils with an outer diameter of $60 \mathrm{~cm}$ and 10 turns of each coil are selected and constructed. Ferrite cores are installed to improve coupling factor. The transfer distance $\mathrm{d}$ between primary and secondary coil are all $15 \mathrm{~cm}$. It is noted that the IPT coil topologies are not considered in this paper, and the coil with circular shaped [13] is adopted for simplicity.

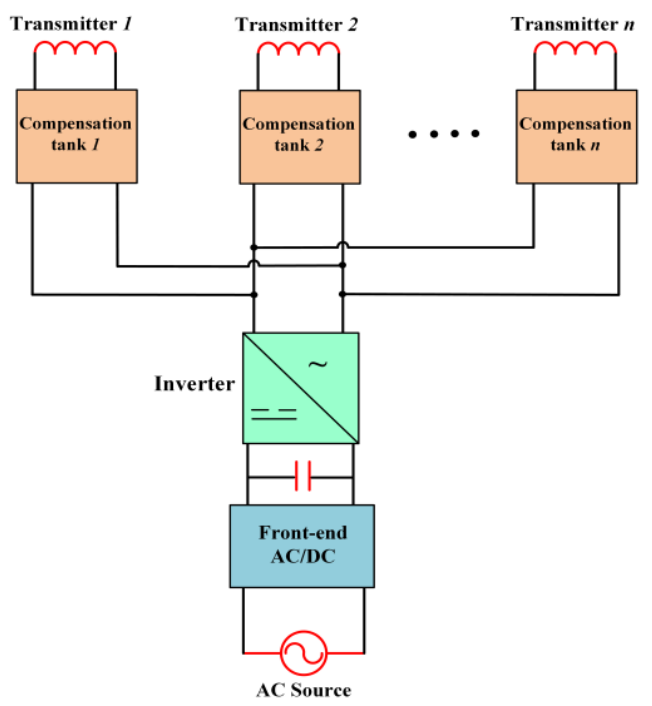

Fig. 1. Concept of proposed multiple output IPT charging station system for $n$ EVs.

The first structure comprises two separated transmitters in primary side $T_{1 a}$ and $T_{2 a}$ and each transmitter are associated with a receiver coil $R_{1 a}$ and $R_{2 a}$, respectively, located on the secondary side. $k_{1 a}$ and $k_{2 a}$ are defined as coupling coefficients between $T_{1 a}$ and $R_{1 a}$ and between $T_{2 a}$ and $R_{2 a}$, respectively, as follows:

$$
k_{1 a}=\frac{M_{1 a}}{\sqrt{L_{T 1 a} L_{R 1 a}}}, \quad k_{2 a}=\frac{M_{2 a}}{\sqrt{L_{T 2 a} L_{R 2 a}}}
$$

Where $L_{T 1 a}$ and $L_{T 2 \mathrm{a}}$ are the self-inductances of $T_{1 a}$ and $T_{2 a}$. Similar, $L_{R 1 a}$ and $L_{R 2 \mathrm{a}}$ are the self-inductances of $R_{1 a}$ and $R_{2 a}$. The mutual inductance between $T_{1 a}$ and $R_{1 a}$ is $M_{1 a}$ while $M_{2 a}$ is one between $T_{2 a}$ and $R_{2 a}$.

The second structure consists of only one transmitter coil $T_{1 b}$ in the primary side with two receivers $R_{1 b}$ and $R_{2 b}$ in the secondary side. $T_{1 b}$ comprises two circular parts in left-hand side covering by $R_{1 b}$ and in right-hand side covering by $R_{2 b}$. These two receivers have the same dimension, volume of ferrites and number of turns as compared to the first structure. $k_{1 b}$ and $k_{2 b}$ are defined as coupling coefficients between $T_{1 b}$ and $R_{1 b}$ and between $T_{1 b}$ and $R_{2 b}$, respectively, as follows:

$$
k_{1 b}=\frac{M_{1 b}}{\sqrt{L_{T 1 b} L_{R 1 b}}}, \quad k_{2 b}=\frac{M_{2 b}}{\sqrt{L_{T 1 b} L_{R 2 b}}}
$$

Where $L_{T 1 b}$ is the self-inductances of $T_{1 b}$ while $L_{R 1 b}$ and $L_{R 2 \mathrm{~b}}$ are the self-inductances of $R_{1 b}$ and $R_{2 b}$, respectively. The mutual inductance between $T_{l b}$ and $R_{l b}$ is $M_{l b}$ while $M_{2 b}$ is one between $T_{1 b}$ and $R_{2 b}$.

To make a fair comparison of two structures in term of coupling coefficient and implementing cost, it is assumed that the length of copper wire for the transmitter in structure $2 T_{l b}$ is chosen to be the same as the total of two transmitters $T_{l a}$ and $T_{2 a}$ in structure 1 . These two structures are simulated in FEA simulation by Maxwell 3D software to determine the coupling coefficient between coils with the simulation models shown in Fig. 2. $D_{C}$ is distant between two channel's coils.

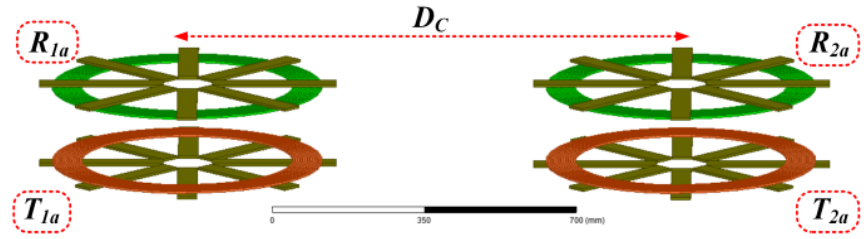

(a) Structure 1

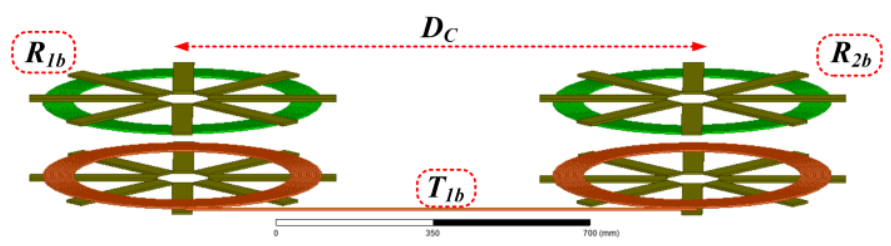

(b) Structure 2

Fig. 2 Simulation models of possible structures

Table I shows simulation results at different values of DC, where: $k_{3}$ is coupling coefficient between $T_{1 a}$ and $T_{2 a}, k_{4}$ is coupling coefficient between $R_{l a}$ and $R_{2 a}, k_{5}$ is coupling coefficient between $T_{1 a}$ and $R_{2 a}, k_{6}$ is coupling coefficient between $T_{2 a}$ and $R_{l a}, k_{7}$ is coupling coefficient between $R_{l b}$ and $R_{2 b}$. Based on the results, the distance DC between two channel's coils is decided to neglect the cross-coupling phenomenon in both structures. The cross-coupling coefficients are cancel when $k_{i}(\mathrm{i}=3,4,5,6) \ll k_{1 a}, k_{2 a}$ for structure 1 and $k_{7} \ll k_{l b}, k_{2 b}$. This condition simplifies the design of compensation tank and control of multiple output IPT system.

TABLE I. MAXWELL-SIMULATED COUPLING COEFFICEINTS

\begin{tabular}{|c|c|c|c|c|c|c|c|}
\hline \multicolumn{6}{|l|}{ Structure 1} \\
\hline$D_{C}$ & $k_{1 a}$ & $k_{2 a}$ & $k_{3}$ & $k_{4}$ & $k_{5}$ & $k_{6}$ \\
\hline $100 \mathrm{~cm}$ & 0.241 & 0.241 & 0.019 & 0.019 & 0.017 & 0.017 \\
\hline $150 \mathrm{~cm}$ & 0.233 & 0.231 & 0.008 & 0.008 & 0.006 & 0.006 \\
\hline Structure 2 & $k_{1 b}$ & $k_{2 b}$ & $k_{7}$ & & & \\
\hline$D_{C}$ & 0.208 & 0.211 & 0.019 & & & \\
\hline $100 \mathrm{~cm}$ & 0.205 & 0.212 & 0.008 & & & \\
\hline $150 \mathrm{~cm}$ & 0.008 & & \\
\hline
\end{tabular}

According to Table I, $k_{1 b}$ and $k_{2 b}$ are slightly smaller than $k_{1 a}$ and $k_{2 a}$, respectively. All cross-coupling coefficient values of structure $1 k_{\mathrm{i}}(\mathrm{i}=3,4,5,6)$ are trivial as compared to $k_{1 a}, k_{2 a}$ when $D_{C}$ is larger more than $150 \mathrm{~cm}$. It is similar in structure 2 when the coupling coefficient between $R_{1 b}$ and $R_{2 b}$ is calculated as 0.008 in the simulation while $k_{1 b}$ and $k_{2 b}$ are 0.205 and 0.212 , respectively. Therefore we can remove the cross-coupling problem from the system when $D_{C} \geq 150 \mathrm{~cm}$ regardless coil's structures. As a result, simplified model of 
two possible structures is presented in Fig. 3 after removing all the cross-coupling coefficient values. Structure 2 is simpler than structure 1 in primary side when it requires only one compensation circuit before $L_{T l b}$. However, it can be deduced from Fig. 3 and Fig 2.b that structure 2 brings higher conduction losses and higher electromagnetic field (EMI) as compared to the first structure when either $L_{R I b}$ or $L_{R 2 b}$ is missing from the system. For example, in case there is the only receiver coil $R_{1 b}$ couples with $T_{1 b}$, the right-hand side part of $T_{1 b}$ still must have current through in even there is no receiver $R_{2 b}$. Consequently, associated losses and an electromagnetic field generated by right-hand side part of $T_{1 b}$ reduce efficiency and raise safety concern to pedestrians, respectively. Therefore, structure 1 is selected to implement the proposed system.

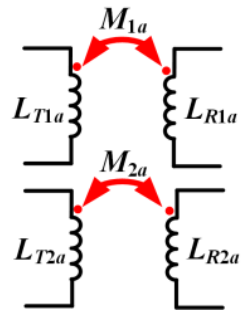

(a) Structure 1

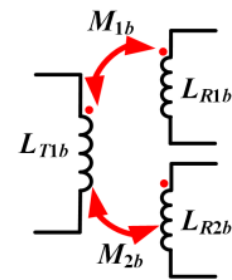

(b) Structure 2
Fig. 3 Simplified models of two possible structures

\section{B. Proposed circuit configuration}

The proposed multiple output inductive charger system is illustrated in Fig. 4. In this configuration, $n$ different output circuits share a full-bridge inverter, which converts the DC input voltage into a high-frequency $\mathrm{AC}$ voltage to feed for primary resonant tanks. The primary inverter operates at a constant switching frequency, which is identical with the resonant frequency of compensation tank. Each battery in secondary side is independently charged by a separate channel, which includes compensation tanks at both sides, a rectifier and a regulator. For channel $i$, the transmitter and receiver coils have the self-inductance of $L_{1 i}$ and $L_{2 i}$, respectively while $M_{i}$ is mutual inductance between them. As discussed in the previous Section II.A, the structure 1 is adopted and the distance between IPT coils of each channel is selected to neglect the effect of cross-coupling of IPT coils between different channels. As a result, the cross-regulation problem of different channels can be solved and each channel can be considered as an independent one. On the secondary side of each channel, the full-bridge rectifier is adopted and a regulator is used as the charging controller. In order to enable one channel to charge its battery, the contactors $S_{a 1}, \ldots S_{a i}, \ldots S_{a n}$ are added at primary side of each channel. Whenever there is a vehicle parking at output number $i$ to charge its battery, the contactor $S_{a i}$ is in ON state. Otherwise, it is in OFF state. In a battery charger system, it usually comprises constant-current (CC) and constant-voltage (CV) mode charge, while $\mathrm{CC}$ mode charge typically stands up for higher energy as compared to CV mode [28]. To improve overall efficiency, IPT load-independent output current topologies should be adopted. Therefore, output battery of each channel is expectedly supplied a nearly constant current in $\mathrm{CC}$ mode without any control if no variation of coupling coefficient is assumed. Battery's voltage in CV mode charge is kept constant by the secondary side regulator, which is not focused in this paper.

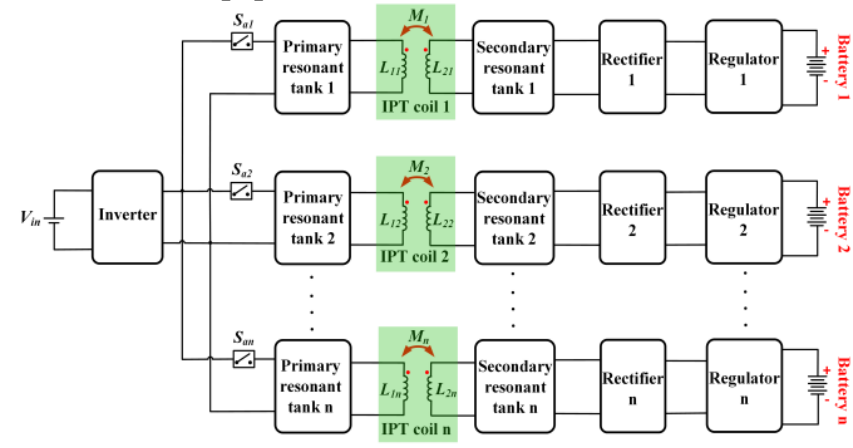

Fig. 4. Proposed multiple output inductive charger for electric vehicles.

\section{IMPLEMENTATION OF PROPOSED MULTIPLE OUTPUT SYSTEM}

\section{A. IPT load-independent output current topologies}

As mentioned before, IPT output load-independent current topology is normally preferred for EV's battery charging. Therefore, an IPT topology family for attaining simultaneous output current sources and ZPA condition is examined in this section. Based on the fact that any impedance matching circuit can be described as T or П-type network [26] and any $\Pi$ network can be transformed to an equivalent $\mathrm{T}$ network, then T-type network is used here for analysis. The two-port network is adopted to facilitate the analysis for simplicity as shown in Fig. 5. The IPT circuit network is driven by a pure sinusoidal ac voltage source $V_{\text {in }}$ with angular frequency $\omega$. Output battery is modelled with an equivalent resistor $R_{A C}$ and battery output voltage and current are $V_{0}$ and $I_{0}$, respectively.

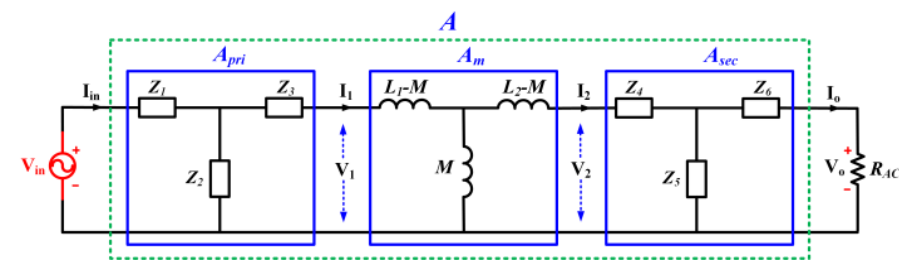

Fig.5. Schematic of an IPT circuit modelled as two-port network using both T-type primary and secondary network

Based on Fig. 5, the relationships between $\left[\begin{array}{l}\mathrm{V}_{\mathrm{o}} \\ \mathrm{I}_{\mathrm{o}}\end{array}\right]$ to $\left[\begin{array}{l}\mathrm{V}_{\text {in }} \\ \mathrm{I}_{\mathrm{in}}\end{array}\right]$ can be depicted as follows:

$$
\left[\begin{array}{l}
\mathrm{V}_{\text {in }} \\
\mathrm{I}_{\text {in }}
\end{array}\right]=A_{\text {pri }} A_{m} A_{\text {sec }}\left[\begin{array}{l}
\mathrm{V}_{\mathrm{o}} \\
\mathrm{I}_{\mathrm{o}}
\end{array}\right]=A\left[\begin{array}{l}
\mathrm{V}_{\mathrm{o}} \\
\mathrm{I}_{\mathrm{o}}
\end{array}\right]
$$

Where $A=\left[\begin{array}{ll}a_{1} & a_{2} \\ a_{3} & a_{4}\end{array}\right]$ is system transmission matrix. $A_{\text {pri }}, A_{m}$ and $A_{\text {sec }}$ represent matrices of primary network, IPT coils and secondary network respectively. The resonant component's impedances $Z_{i}(i=1-6)$ are either inductance or capacitance. To simplify, all AC resistances of the network are neglected in this analysis. It should be reminded that $\mathrm{V}_{\mathrm{O}}=$ $R_{A C} \mathrm{I}_{\mathrm{o}}$ and the output current $\mathrm{I}_{\mathrm{o}}$ can be presented as (4) based on (3).

$$
\frac{\mathrm{I}_{\mathrm{o}}}{\mathrm{V}_{\mathrm{in}}}=\frac{1}{a_{1} R_{A C}+a_{2}}
$$

In order to achieve constant output current $\mathrm{I}_{\mathrm{o}}, a_{1}$ in (4) should be equal 0 while $a_{2}$ must differ 0 . To attain it, we 
calculate $a_{1}$ according two-port network circuit in Fig. 5 and then the conditions for $Z_{i}(i=1-6)$ are determined. On the other hand, the input impedance of an IPT circuit in Fig. 5(a) is depicted as follows:

$$
Z_{\text {in }}=\frac{\mathrm{V}_{\text {in }}}{\mathrm{I}_{\text {in }}}=\frac{a_{1} \mathrm{~V}_{\mathrm{o}}+a_{2} \mathrm{I}_{\mathrm{o}}}{a_{3} \mathrm{~V}_{\mathrm{o}}+a_{4} \mathrm{I}_{\mathrm{o}}}=\frac{a_{1} R_{A C}+a_{2}}{a_{3} R_{A C}+a_{4}}
$$

Linking to matrices of cascading subnetworks $A_{\text {pri }}, A_{m}$ and $A_{\text {sec }}, a_{i}(\mathrm{i}=1,2,3,4)$ are determined as (6).

$$
\left\{\begin{array}{l}
a_{1}=d_{1}\left(b_{1} c_{1}+b_{2} c_{3}\right)+d_{3}\left(b_{1} c_{2}+b_{2} c_{4}\right) \\
a_{2}=d_{2}\left(b_{1} c_{1}+b_{2} c_{3}\right)+d_{4}\left(b_{1} c_{2}+b_{2} c_{4}\right) \\
a_{3}=d_{1}\left(b_{3} c_{1}+b_{4} c_{3}\right)+d_{3}\left(b_{3} c_{2}+b_{4} c_{4}\right) \\
a_{4}=d_{2}\left(b_{3} c_{1}+b_{4} c_{3}\right)+d_{4}\left(b_{3} c_{2}+b_{4} c_{4}\right)
\end{array}\right.
$$

The constrain to achieve ZPA condition for input impedance of an IPT circuit is:

$$
\operatorname{Im}\left(\frac{a_{1} R_{A C}+a_{2}}{a_{3} R_{A C}+a_{4}}\right)=0
$$

The relationships of voltage and current of each cascading subnetworks are expressed as (8):

$$
\left\{\begin{array}{l}
{\left[\begin{array}{l}
\mathrm{V}_{\text {in }} \\
\mathrm{I}_{\text {in }}
\end{array}\right]=A_{\text {pri }}\left[\begin{array}{l}
\mathrm{V}_{1} \\
\mathrm{I}_{1}
\end{array}\right]} \\
{\left[\begin{array}{l}
\mathrm{V}_{1} \\
\mathrm{I}_{1}
\end{array}\right]=A_{m}\left[\begin{array}{l}
\mathrm{V}_{2} \\
\mathrm{I}_{2}
\end{array}\right]} \\
{\left[\begin{array}{l}
\mathrm{V}_{2} \\
\mathrm{I}_{2}
\end{array}\right]=A_{\text {sec }}\left[\begin{array}{l}
\mathrm{V}_{\mathrm{o}} \\
\mathrm{I}_{\mathrm{o}}
\end{array}\right]}
\end{array}\right.
$$

In which $A_{\text {pri }}, A_{m}$ and $A_{\text {sec }}$ can be found as (9)

$$
\left\{\begin{array}{c}
A_{\text {pri }}=\left[\begin{array}{ll}
b_{1} & b_{2} \\
b_{3} & b_{4}
\end{array}\right]=\left[\begin{array}{cc}
1+\frac{Z_{1}}{Z_{2}} & Z_{1}+Z_{3}+\frac{Z_{3} Z_{1}}{Z_{2}} \\
\frac{1}{Z_{2}} & 1+\frac{Z_{3}}{Z_{2}}
\end{array}\right] \\
A_{m}=\left[\begin{array}{ll}
c_{1} & c_{2} \\
c_{3} & c_{4}
\end{array}\right]=\left[\begin{array}{cc}
\frac{L_{1}}{M} & -j \omega\left(\frac{L_{1} L_{2}}{M}+M\right) \\
\frac{1}{j \omega M} & -\frac{L_{2}}{M}
\end{array}\right] \\
A_{\text {sec }}=\left[\begin{array}{ll}
d_{1} & d_{2} \\
d_{3} & d_{4}
\end{array}\right]=\left[\begin{array}{cc}
1+\frac{Z_{4}}{Z_{5}} & Z_{4}+Z_{6}+\frac{Z_{6} Z_{4}}{Z_{5}} \\
\frac{1}{Z_{5}} & 1+\frac{Z_{6}}{Z_{5}}
\end{array}\right]
\end{array}\right.
$$

Therefore, $a_{i}(\mathrm{i}=1,2,3,4)$ are determined as (10). To guarantee achieving simultaneous output current sources and ZPA condition, $Z_{i}(i=1-6)$ need to be selected to meet simultaneously: (1) $a_{1}=0$ and (2) $\operatorname{Im}\left(\frac{a_{1} R_{A C}+a_{2}}{a_{3} R_{A C}+a_{4}}\right)=0$.

\section{B. Option 1: each channel operating at ZPA frequency}

As mentioned in the Introduction part, two methods to realize the proposed system are suggested as shown in Fig. 6. The straight way is to operate compensation tank of each channel at exact its ZPA frequencies as depict in Fig. 6a. Therefore, the ZPA for total input impedance of primary inverter can be achieved as a result. Compensation topology for each channel can be the same or different, however, ZPA frequencies must be identical for all channels and equal to the switching frequency of inverter. Several typical topologies with constant-current output characteristic are selected to evaluate the analysis in Section III.A. Next, their features concerning Zero Phase Angle conditions and number of resonant components are compared to select the most suitable IPT compensation topology for the proposed multiple output system.

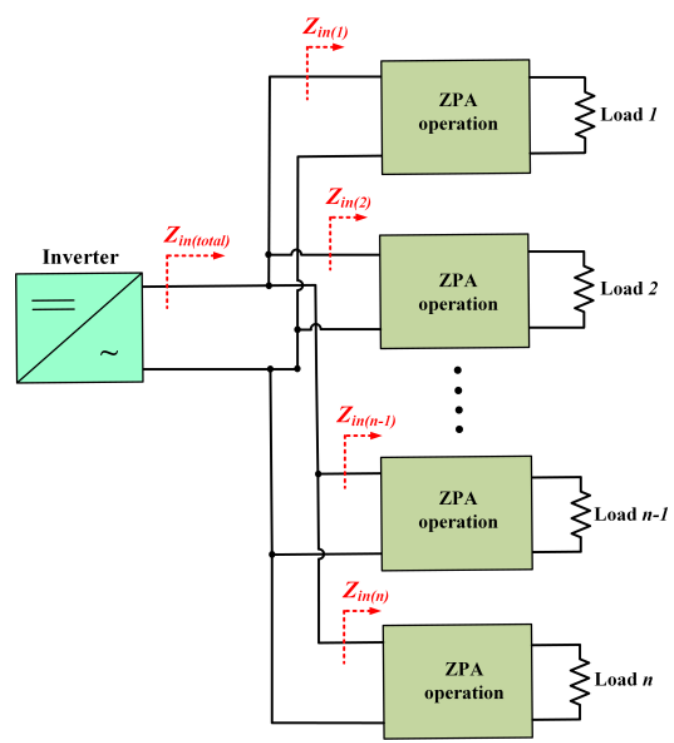

(a) Option 1

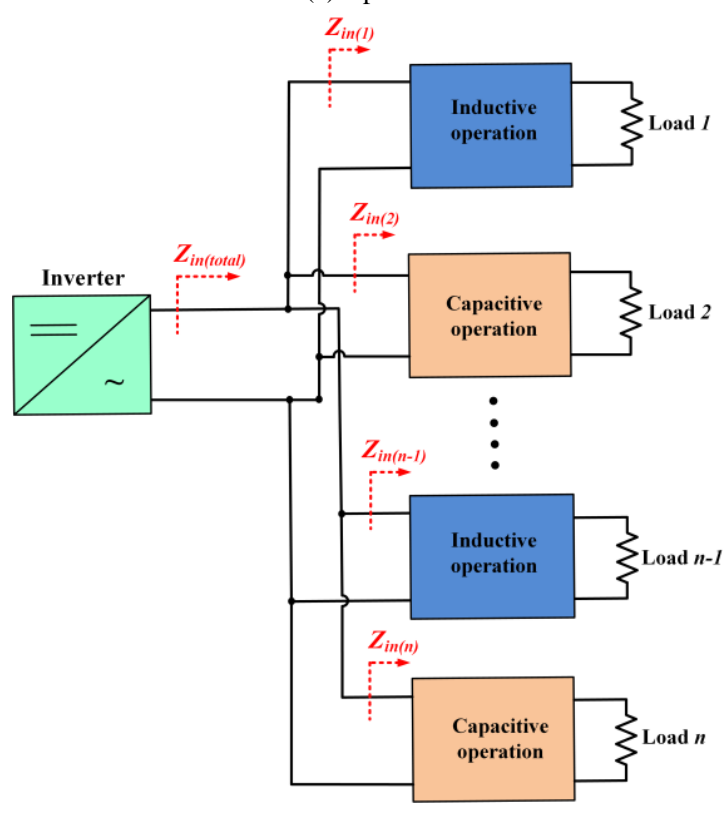

(b) Option 2

Fig. 6. Two options to operate the proposed system

$$
\left\{\begin{array}{c}
a_{1}=\left(1+\frac{Z_{4}}{Z_{5}}\right)\left[\frac{L_{1}}{M}\left(1+\frac{Z_{1}}{Z_{2}}\right)+\frac{1}{j \omega M}\left(Z_{1}+Z_{3}+\frac{Z_{3} Z_{1}}{Z_{2}}\right)\right]+\frac{1}{Z_{5}}\left[-\left(1+\frac{Z_{1}}{Z_{2}}\right) j \omega\left(\frac{L_{1} L_{2}}{M}+M\right)-\left(Z_{1}+Z_{3}+\frac{Z_{3} Z_{1}}{Z_{2}}\right) \frac{L_{2}}{M}\right] \\
a_{2}=\left(Z_{4}+Z_{6}+\frac{Z_{6} Z_{4}}{Z_{5}}\right)\left[\frac{L_{1}}{M}\left(1+\frac{Z_{1}}{Z_{2}}\right)+\frac{1}{j \omega M}\left(Z_{1}+Z_{3}+\frac{Z_{3} Z_{1}}{Z_{2}}\right)\right]+\left(1+\frac{Z_{6}}{Z_{5}}\right)\left[-\left(1+\frac{Z_{1}}{Z_{2}}\right) j \omega\left(\frac{L_{1} L_{2}}{M}+M\right)-\left(Z_{1}+Z_{3}+\frac{Z_{3} Z_{1}}{Z_{2}}\right) \frac{L_{2}}{M}\right] \\
a_{3}=\left(1+\frac{Z_{4}}{Z_{5}}\right)\left[\frac{L_{1}}{M Z_{2}}+\frac{1}{j \omega M}\left(1+\frac{Z_{3}}{Z_{2}}\right)\right]+\frac{1}{Z_{5}}\left[\frac{-j \omega}{Z_{2}}\left(\frac{L_{1} L_{2}}{M}+M\right)-\left(1+\frac{Z_{3}}{Z_{2}}\right) \frac{L_{2}}{M}\right] \\
a_{4}=Z_{4}+Z_{6}+\frac{Z_{6} Z_{4}}{Z_{5}}\left[\frac{L_{1}}{M Z_{2}}+\frac{1}{j \omega M}\left(1+\frac{Z_{3}}{Z_{2}}\right)\right]+\left(1+\frac{Z_{6}}{Z_{5}}\right)\left[\frac{-j \omega}{Z_{2}}\left(\frac{L_{1} L_{2}}{M}+M\right)-\left(1+\frac{Z_{3}}{Z_{2}}\right) \frac{L_{2}}{M}\right]
\end{array}\right.
$$


LCC-P topology in [27] and LCC-LCC topology in [10] are discussed and evaluated here as examples. The circuit configuration of LCC-P compensation topology is depicted in Fig. 7. This topology can be represented by model in Fig. 5 with $Z_{4}=Z_{6}=0$. The conditions to attain constant output current is:

$$
\begin{gathered}
a_{1}(\mathrm{LCC}-\mathrm{P})=\left[\frac{L_{1}}{M}\left(1+\frac{Z_{1}}{Z_{2}}\right)+\frac{1}{j \omega M}\left(Z_{1}+Z_{3}+\frac{Z_{3} Z_{1}}{Z_{2}}\right)\right] \\
+\frac{1}{Z_{5}}\left[-\left(1+\frac{Z_{1}}{Z_{2}}\right) j \omega\left(\frac{L_{1} L_{2}}{M}+M\right)\right. \\
\left.-\left(Z_{1}+Z_{3}+\frac{Z_{3} Z_{1}}{Z_{2}}\right) \frac{L_{2}}{M}\right]=0
\end{gathered}
$$

Where: $Z_{1}=j \omega L_{1 p}, Z_{2}=\frac{1}{j \omega C_{2 p}}, Z_{3}=\frac{1}{j \omega C_{1 p}}$ and $Z_{4}=$ $\frac{1}{j \omega C_{2 s}}$.

It is noted that keeping constant the primary coil current $I_{1}$ is the main advantage of primary-LCC topology. To achieve it $L_{1 p}$ must be resonated with $C_{2 p}$ at resonant frequency $\omega_{o}$. In other words $Z_{1}+Z_{2}=0$, therefore, the conditions in Eq. 11 can be simplified as:

$$
Z_{5}-j \omega_{o} L_{2}=0
$$

As a result, output current $I_{0}$, which depends on only input voltage and resonant components, can be calculated according to (4) with $a_{2}=\frac{-Z_{1} L_{2}}{M}$.

$$
\mathrm{I}_{\mathrm{o}}=-j \omega_{o}^{3} C_{2 p} C_{2 s} M \mathrm{~V}_{\text {in }}
$$

On the other hand, Eq. (14) below is used to determine input impedance of LCC-P topology according to (7):

Where $A=\frac{(\omega M)^{2} C_{2 s} R_{A C}}{L_{2}}, B=\omega L_{1}-\frac{1}{\omega C_{2 p}}-\frac{1}{\omega C_{1 p}}+\frac{(\omega M)^{2} R_{A C}}{\omega L_{2}}$. To achieve ZPA operation at resonant frequency $\omega_{o}$, $\operatorname{Im}\left[Z_{\text {in }}(\mathrm{LCC}-\mathrm{P})\right]=B=0$ regardless of the load condition. However, $B$ depends on the equivalent load $R_{A C}$, it relates to the state of charge of battery. Therefore, LCC-P compensation topology cannot achieve ZPA condition at CC mode charge.

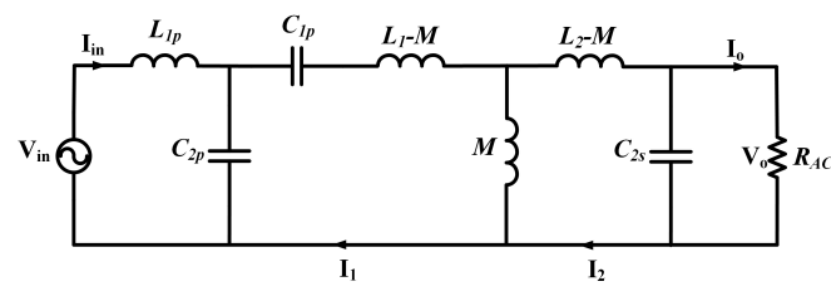

Fig. 7. $\quad A C$ equivalent circuit of LCC-P compensation topology

The other popular current source IPT topology LCC-LCC [10] with $A C$ equivalent circuit in Fig. 8.a is also evaluated and discussed here. The constraints of resonant tank to contemporarily attain load-independent current and ZPA operation are mentioned based on analysis in Section III.A. The circuit configuration can be also represented based on Fig. 5 with $Z_{1}=j \omega L_{1 p}, Z_{2}=\frac{1}{j \omega C_{2 p}}, Z_{3}=\frac{1}{j \omega C_{1 p}}, Z_{4}=$ $\frac{1}{j \omega C_{1 s}}, Z_{5}=\frac{1}{j \omega C_{2 s}}$ and $Z_{6}=j \omega L_{1 s} . \quad$ Similar as LCC-P topology, primary coil current is also kept constant in LCCLCC topology. It leads to the constraint of $Z_{1}+Z_{2}=0$ and $a_{1}$ in (10) can be simplified as follows:

$$
a_{1}(\mathrm{LCC}-\mathrm{LCC})=\left(1+\frac{Z_{4}}{Z_{5}}\right) \frac{Z_{1}}{j \omega M}-\frac{Z_{1} L_{2}}{Z_{5} M}
$$

Output current $\mathrm{I}_{\mathrm{o}}$ can be achieved constantly if resonant tank of LCC-LCC topology is designed at $\omega_{o}$ follows (16).

$$
Z_{4}+Z_{5}-j \omega_{o} L_{2}=0
$$

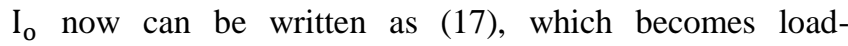
independent:

$$
\mathrm{I}_{\mathrm{o}}=-j \omega_{o}^{3} C_{2 p} C_{2 s} M \mathrm{~V}_{\mathrm{in}}
$$

The input impedance of this topology is also defined based on Eq. (5) in which $a_{i}(i=1-4)$ are simplified with constraints of $Z_{1}+Z_{2}=0$ and (16).

$$
\begin{gathered}
Z_{\text {in }}(\mathrm{LCC}-\mathrm{LCC})=Z_{1}+ \\
\frac{Z_{2}\left[j \omega L_{1}+Z_{3}-\frac{(\omega M)^{2}}{\left.j \omega L_{2}+Z_{4}+\frac{Z_{5}\left(Z_{6}+R_{A C}\right)}{Z_{5}+Z_{6}+R_{A C}}\right]}\right.}{\left[j \omega L_{1}+Z_{3}+Z_{2}-\frac{(\omega M)^{2}}{j \omega L_{2}+Z_{4}+\frac{Z_{5}\left(Z_{6}+R_{A C}\right)}{Z_{5}+Z_{6}+R_{A C}}}\right]}
\end{gathered}
$$

The imaginary part of $Z_{\text {in }}$ (LCC - LCC) has to be eliminated in order to achieve the ZPA condition. It results in the condition in (19).

$$
\left\{\begin{array}{c}
Z_{5}+Z_{6}=0 \\
j \omega L_{1}+Z_{2}+Z_{3}=0
\end{array}\right.
$$

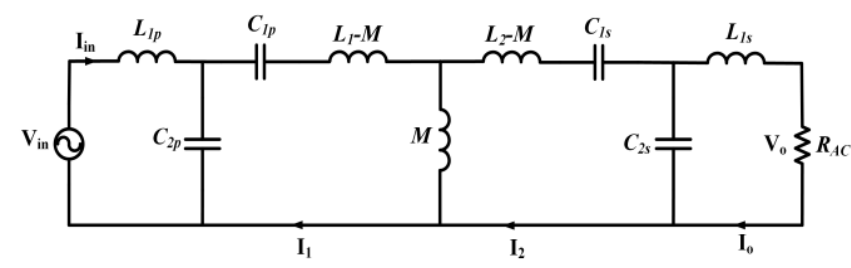

(a)

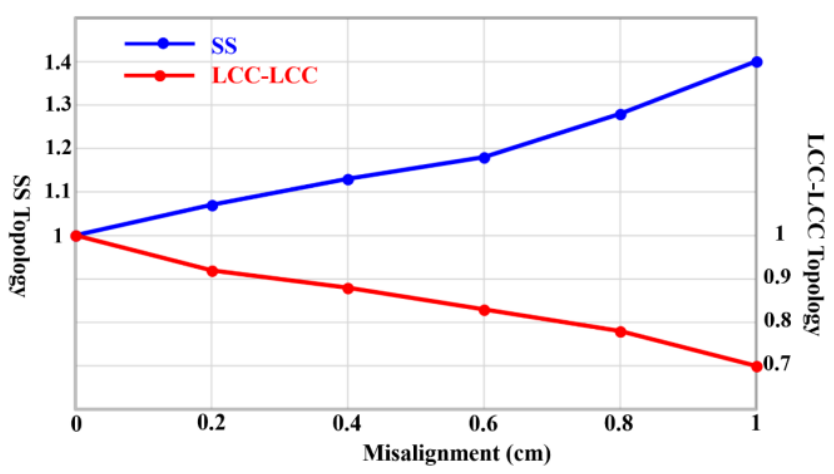

(b)

Fig. 8. (a) $A C$ equivalent circuit of LCC-LCC compensation topology, (b) Normalized output current versus misalignment for SS and LCC-LCC topologies

$$
Z_{\text {in }}(L C C-P)=j \omega_{o} L_{1 p}+\frac{\frac{1}{j \omega_{o} C_{2 p}}\left[\frac{1}{j \omega_{o} C_{1 p}}+j \omega_{o} L_{1}-\frac{\left(R_{A C}-j \omega_{o} L_{2}\right)\left(\omega_{o} M\right)^{2}}{\left(\omega_{o} L_{2}\right)^{2}}\right]}{\frac{1}{j \omega_{o} C_{2 n}}+\frac{1}{j \omega_{o} C_{1 n}}+j \omega_{o} L_{1}-\frac{\left(R_{A C}-j \omega_{o} L_{2}\right)\left(\omega_{o} M\right)^{2}}{\left(\omega_{o} L_{2}\right)^{2}}}=\frac{-1}{\left(\omega_{o} C_{2 p}\right)^{2}\left(A^{2}+B^{2}\right)}(A+j B)
$$


Analysis and calculation in Section III.A can be applied for any other IPT resonant topology as well. As a result, main characteristics of six popular load-independent current IPT topologies are listed in Table II to select the most suitable one for the proposed system operating based on Option 1. These topologies include Series-Series (SS) [29], Series-Parallel (SP) [30], Parallel-Parallel (PP) [31], LCL-LCL [7], LCC-P [27] and LCC-LCC [10]. The first criterion mentioning in Table II is independent resonant frequency. An IPT system always would prefer to operate at resonance condition, and it results in an improvement of power transfer capability and overall efficiency. However, the resonant frequency is not always constant in some topologies consisting of SP or PP due to the variation of mutual inductance $M$ between transmitter and receiver coils. Therefore, these two topologies are not suitable for the proposed system. The second criterion is ZPA operation, which helps to minimize reactive powers in IPT circuit. This criterion is not able to achieve in case of both SP and LCC-P topologies. Also, the robustness of output current $\mathrm{I}_{\mathrm{o}}$ according to $M$ is also vital in the IPT charger. In case of SS topology, output current and power are inversely proportional to mutual inductance. To keep the same $\mathrm{I}_{\mathrm{o}}$ when $M$ reduces of SS topology, then input voltage $\mathrm{V}_{\text {in }}$ has to be decreased resulting in an increase of $\mathrm{I}_{\mathrm{in}}$. It consequences in an increase of conduction losses in the primary circuit and EMI from transmitter coil as well. Moreover, protection is required to stop charger when $M$ drops to be below the certain range, and input power exceeds the limited value. Fig. $8 \mathrm{~b}$ depicts simulation results to compare the robustness of output current $\mathrm{I}_{\mathrm{o}}$ between SS and LCC-LCC topologies under variation of $M$. We can clearly see that when $M$ reduces under misalignment conditions from 0 to $10 \mathrm{~cm}$, then $\mathrm{I}_{\mathrm{o}}$ of $\mathrm{SS}$ case rises to 1.4 times of normal value while it decreases to 0.7 times in LCCLCC case, respectively. The flexible in the design of resonant tank is another important criterion. The more resonant components involve in, the more flexible to adjust output current is. In an IPT charger, the areas to install IPT coils are normally limited; therefore, self-inductances $L_{1}$ and $L_{2}$ are also limited. Coupling coefficient is assumed to be $0.1 \sim 0.25$ with the standard distance of $15 \sim 20 \mathrm{~cm}$ between transmitter and receiver coil for EV's application. Moreover, switching frequency is also recommended around $85 \mathrm{kHz}$ according to upcoming standard SAE J2954 for static wireless charging [32]. Therefore, extra parameters to adjust the output current and power are necessary in many cases. Topologies of LCC-P and LCC-LCC can meet this requirement thanks to two additional capacitors $C_{2 p}$ and $C_{2 s}$. Next criterion is number of resonant components in compensation tank. The less resonant components, the more advantageous to design and optimize of the overall system. The last thing we need to take into consideration is value of additional inductors of several topologies. Both PP and LCL-LCL topologies require additional inductors at one or both sides, where inductance values are normally similar to those of coils and that, consequentially, makes system becoming bulky. In contrast, additional inductors in LCC-P and LCC-LCC can be freely designed and their value can select significantly smaller than the coil's values.

From above comparisons, LCC-LCC compensation topology is decided to implement for each channel of the proposed system when every channel works at ZPA operation. However, the proposed system is fine to work with other topologies. For lower cost resulting by mass production and maintenance reasons, all channels should be built by using the same topology in practical implementation. Depending on specifications and requirements of specific application, the suitable topology can be selected.

\section{Option 2: each channel not operating at ZPA frequency}

From Table II, double-sided LCL and LCC topologies show better features in terms of ZPA achievement and robustness of current. However, number of resonant components are greater significant as compared to basic topologies (SS, SP or PP). In some applications requiring low cost and small circuit volume, these two above topologies in [7] and [10] may not be suitable. Therefore, the simpler topologies should be considered with advantages of reducing number of resonant components. ZPA operation of primary inverter is impossible to achieve for conventional singleoutput system, however, it is possible in the case of multiple output system. This section proposes the other method to achieve ZPA operation for primary inverter which bases on the interaction between compensation tanks of two channels. IPT compensation tank could provide some load-independent frequencies in which the ZPA operation for input impedance cannot attain. The main idea here is that one channel can be designed to operate in inductive region and the other in capacitive region of input impedance. By using an appropriate design, the reactive powers of these two tanks can be nearly cancelled each other and inverter current can be in phase with input voltage as a result. If we can attain it, then the power source only needs to provide the real power to all channel's loads. Therefore, stresses on components in the PFC stage and primary inverter can be significantly reduced. However, stresses on resonant capacitors and the coils are still kept nearly the same as single output system. This paper illustrates for two channels only, however, this principle can be adopted for any number of channels. Fig 9 illustrates the concept where S, S1, S2 are apparent powers suppling for whole system, channel 1 and channel 2 respectively. P, P1, P2 and Q, Q1, Q2 are the real and reactive powers providing for the system and two channels respectively. Relationship between them is expressed by Eq. (20).

$$
\left\{\begin{array}{c}
S=P+j Q \\
S_{1}=P_{1}+j Q_{1} \\
S_{2}=P_{2}+j Q_{2}
\end{array}\right.
$$

The cancelation of total reactive power $Q=Q_{1}+Q_{2}$ happens if one of two following conditions is satisfied:

(1) $Q_{1}=Q_{2}=0$ : both compensation tanks attain ZPA, which is already mentioned above in Section III.1

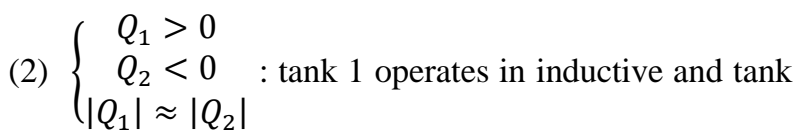
2 is in capacitive region with the same magnitude of reactive power

(3) $\left\{\begin{array}{c}Q_{1}<0 \\ Q_{2}>0 \\ \left|Q_{1}\right| \approx\left|Q_{2}\right|\end{array}\right.$ : tank 1 operates in capacitive and tank 2 is in inductive region with the same magnitude of reactive power. 


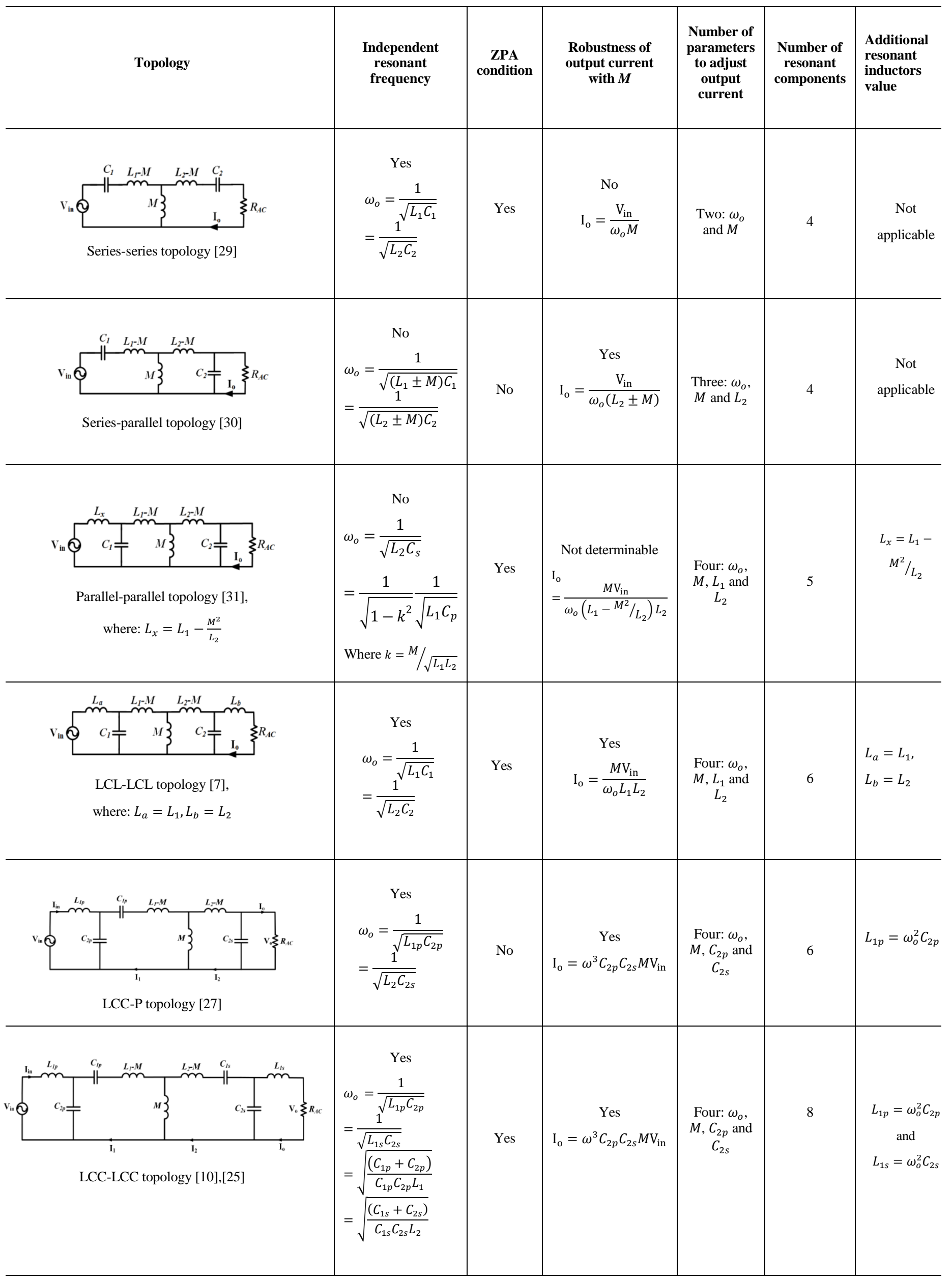




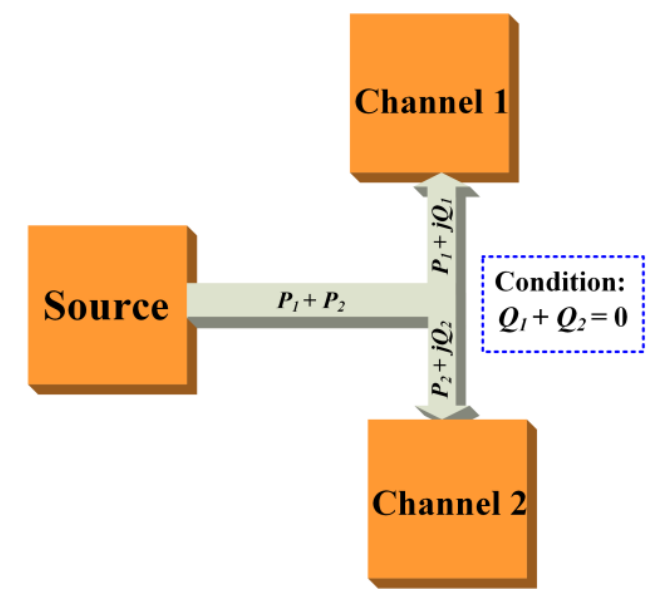

Fig. 9 The overall principle of achieving ZPA with two different compensation tanks

To illustrate above proposed concept, the analysis of the Series-Parallel (SP) topology is conducted as an example. Fig. 10 depicts AC equivalent circuit for SP topology where $L_{1}, L_{2}$ are the self-inductances of primary and secondary coils while $M$ is the mutual inductance between them. The resonant capacitors in primary and secondary sides are $C_{1}$ and $C_{2}$ respectively. Transconductance gain, voltage gain and input impedance are depicted respectively as (21), (22) and (23) by applying Eqs (3-5) with $Z_{1}=\frac{1}{j \omega C_{1}}, Z_{2}=\infty, Z_{3}=Z_{4}=$ $Z_{6}=0$ and $Z_{5}=\frac{1}{j \omega C_{2}}$.

$$
\begin{gathered}
G_{i}=\frac{I_{o}}{V_{i n}}=\frac{1}{\left(1+j \omega C_{2} R_{A C}\right)} * \\
\frac{j \omega M}{\left[\left(j \omega L_{2}+\frac{R_{A C}}{1+j \omega C_{2} R_{A C}}\right)\left(j \omega L_{1}+\frac{1}{j \omega C_{1}}\right)+(\omega M)^{2}\right]} \\
G_{v}=\frac{V_{o}}{V_{i n}}=\frac{1}{\left(1+j \omega C_{2} R_{A C}\right)} * \\
{\left[\left(j \omega L_{2}+\frac{R_{A C}}{1+j \omega C_{2} R_{A C}}\right)\left(j \omega L_{1}+\frac{1}{j \omega C_{1}}\right)+(\omega M)^{2}\right]}
\end{gathered}
$$

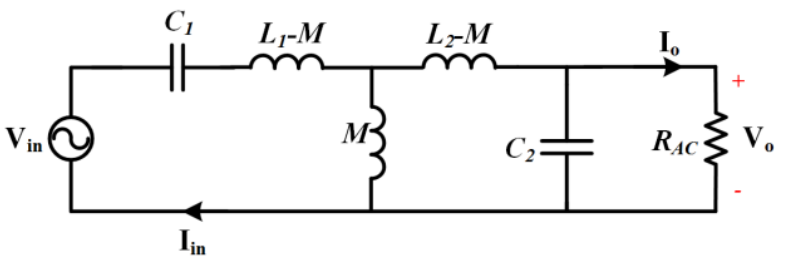

Fig. 10 AC equivalent circuit of SP topology

Conditions to attain constant output current for SP topology based on the analysis in Section III.A depict as (24).

$$
\begin{gathered}
a_{1}(S P)=\frac{L_{1}}{M}+\frac{Z_{1}}{j \omega M}-\frac{j \omega}{Z_{5}}\left(\frac{L_{1} L_{2}}{M}+M\right) \\
-\frac{Z_{1} L_{2}}{Z_{5} M}=0
\end{gathered} \begin{aligned}
& \begin{array}{l}
\text { two channels are selected as the same, the } \\
\text { between } C_{11} \text { and } C_{12} \text { can be depicted as }(28) \\
k \text { and } L_{11}=L_{12}=L_{1} .
\end{array} \\
& Z_{\text {in }}(\mathrm{SP})=\frac{\left[\frac{L_{1}}{M}+\frac{1}{(j \omega M)\left(j \omega C_{1}\right)}+\omega^{2} C_{2}\left(\frac{L_{1} L_{2}}{M}+M\right)-\frac{L_{2} C_{2}}{M C_{1}}\right] R_{A C}-j \omega\left(\frac{L_{1} L_{2}}{M}+M\right)-\frac{L_{2}}{j \omega C_{1} M}}{\left(\frac{1}{j \omega M}-\frac{j \omega C_{2} L_{2}}{M}\right) R_{A C}-\frac{L_{2}}{M}}
\end{aligned}
$$

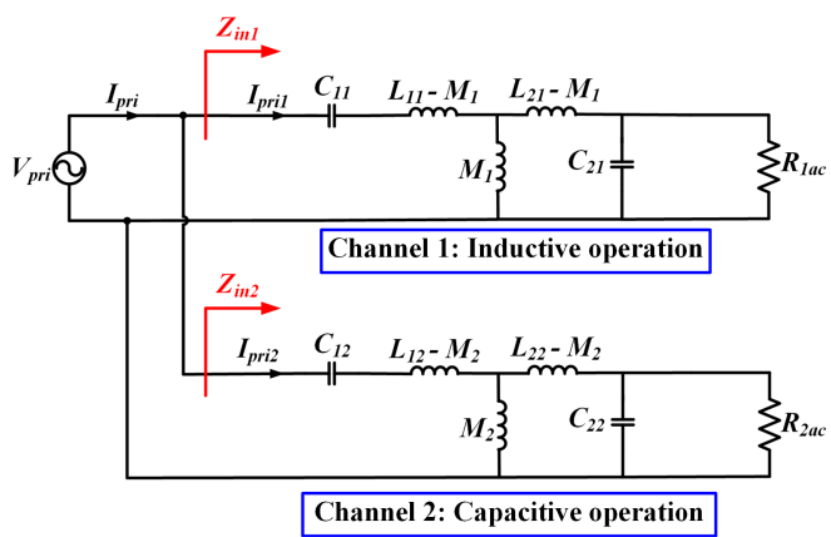

Fig. 11 Two-channel system based on option 2 operation with SP topology

Solving Eq. (24), there are two load-independent current frequencies namely $\omega_{C C a}$ and $\omega_{C C b}$ expressing in (25) while $\omega_{C V}$ in (26) is for output voltage source. In this work, $L_{1}$ and $L_{2}$ are assumed to be identical for simplicity.

$$
\left\{\begin{array}{c}
\omega_{C C a}=\frac{1}{\sqrt{(1-k) L_{1} C_{1}}}=\frac{1}{\sqrt{(1-k) L_{2} C_{2}}} \\
\omega_{C C b}=\frac{1}{\sqrt{(1+k) L_{1} C_{1}}}=\frac{1}{\sqrt{(1+k) L_{2} C_{2}}} \\
\omega_{C V}=\frac{1}{\sqrt{\left(1-k^{2}\right) L_{1} C_{1}}}=\frac{1}{\sqrt{L_{2} C_{2}}}
\end{array}\right.
$$

Output currents at $\omega_{C C a}$ and $\omega_{C C b}$ are depicted as $I_{O 1}$ and $I_{O 2}$ in (27) which are independent with the load condition.

$$
\left\{\begin{array}{l}
I_{o 1}=\frac{V_{\text {in }}}{j \omega(1-k) L_{2}} \\
I_{o 2}=\frac{V_{\text {in }}}{j \omega(1+k) L_{2}}
\end{array}\right.
$$

By calculating $Z_{i n}(\mathrm{SP})$ at $\omega_{C C a}$ and $\omega_{C C b}$, it can be clearly seen that SP topology operates as inductive at $\omega_{C C a}$ and capacitive at $\omega_{C C b}$. Compensation tank 1 of Channel 1 can be designed to operate at around $\omega_{C C a}$ in inductive region while compensation tank 2 of Channel 2 operates at around $\omega_{C C b}$. Because two tanks share the same inverter, therefore, $\omega_{C C a}$ and $\omega_{C C b}$ have to be identical. Fig. 11 shows twochannel system with SP topology. It leads to Eq. (28) below:

$$
\begin{gathered}
\omega_{C C a 1}=\omega_{C C b 2}=> \\
\frac{1}{\sqrt{\left(1-k_{1}\right) L_{11} C_{11}}}=\frac{1}{\sqrt{\left(1+k_{2}\right) L_{12} C_{12}}}
\end{gathered}
$$

Where $k_{1}, L_{11}$ and $C_{11}$ are the coupling factor, selfinductance of coils and primary capacitor for Channel 1 respectively while $k_{2}, L_{12}$ and $C_{12}$ are corresponding parameters for Channel 2. It is assumed that the IPT coils of two channels are selected as the same, then the relationship between $C_{11}$ and $C_{12}$ can be depicted as (28) where $k_{1}=k_{2}=$ 


$$
C_{12}=\frac{1-k}{1+k} C_{11}
$$

$C_{11}$ is determined based on Eq (25) after the IPT coils parameters are selected and the inverter's frequency is decided. Then $C_{12}$ is calculated by Eq. (28). To verify the above design, simulations of transconductance gain $G_{i}$ and phase of $Z_{\text {in }}$ are conducted and shown in Fig. 12 (a) and (b). The inverter frequency is set as $80 \mathrm{kHz}$. According to Fig. 12, Channel 1 operates at $f_{C C a 1}\left(\frac{\omega_{C C a 1}}{2 \pi}\right)$ in the inductive region while Channel 2 works at $f_{C C b 2}\left(\frac{\omega_{C C b 2}}{2 \pi}\right)$ in the capacitive region. It is noted that if there is only one output battery requiring to charge, then the operation of proposed system is conducted at the output constant voltage frequency. For example, if only Channel 1 is required, switching frequency of $76 \mathrm{kHz}$ will be activated to be identical $f_{C V 1}$ according to Fig. 12(a). ZPA operation is guaranteed for Channel 1 as a result at around $f_{C V 1}$.

It is also necessary to present the relationship of phase difference $\varphi$ between $V_{p r i}$ and $I_{p r i}$ and load resistances $R_{1 a c}$ and $R_{2 a c}$. Firstly, the expressions of channel 1 input current $I_{\text {pri1 } 1}$, channel 2 input current $I_{\text {pri2 }}$ and inverter output current $I_{\text {pri }}$ depend on inverter output voltage $V_{\text {pri }}$, load and other resonant components are derived. Input impedances $Z_{\text {in } 1}$ and $Z_{\text {in } 2}$ are depicted as (30a) and (30b) for channels 1 at $\omega_{C C a}$ and 2 at $\omega_{C C b}$, respectively. Obviously, $\omega_{C C a}=\omega_{C C b}=$ $\omega_{o}=2 \pi f_{o}$ where is switching frequency of inverter.

$$
\begin{gathered}
Z_{i n 1}=\left(j \omega_{o} M_{1}\right) \|\left[j \omega_{o}\left(L_{21}-M_{1}\right)\right. \\
\left.+\frac{1}{j \omega_{o} C_{21}} \| R_{1 a c}\right] \\
=\frac{\omega_{o} M_{1}\left(L_{21}-M_{1}\right)}{\omega_{o} M_{1} C_{21} R_{1 a c}-j L_{21}} \\
Z_{\text {in } 2}=-2 j \omega_{o} M_{2}+\left(j \omega_{o} M_{2}\right) \|\left[j \omega_{o}\left(L_{22}-M_{2}\right)\right. \\
\left.+\frac{1}{j \omega_{o} C_{22}} \| R_{2 a c}\right] \\
=\frac{\omega_{o} M_{2}\left(L_{22}+M_{2}\right)}{\omega_{o} M_{2} C_{22} R_{2 a c}-j L_{22}}
\end{gathered}
$$

Input current of Channel $1 I_{\text {pri1 }}$ can be defined as (31)

$$
I_{\text {pri1 }}=\frac{V_{p r i}}{Z_{\text {in } 1}}=\frac{V_{\text {pri }}}{\omega_{o} M_{1}\left(L_{21}-M_{1}\right)}\left(\omega_{o} M_{1} C_{21} R_{1 a c}-j L_{21}\right)
$$

Then the amplitude $\mathbf{I}_{\text {pri1 }}$ and phase $\varphi_{1}$ of $I_{\text {pri1 }}$ can be determined as (32), where $\varphi_{1}$ is a negative number.

$$
\left\{\begin{array}{c}
\mathbf{I}_{\text {pri1 }}=\frac{V_{\text {pri }} \sqrt{\left(\omega_{o} M_{1} C_{21} R_{1 a c}\right)^{2}+L_{21}^{2}}}{\omega_{o} M_{1}\left(L_{21}-M_{1}\right)} \\
\varphi_{1}=\tan ^{-1}\left(\frac{-L_{21}}{\omega_{o} M_{1} C_{21} R_{1 a c}}\right)<0^{o}
\end{array}\right.
$$

Similarly for channel 2 , in which $I_{\text {pri2 }}$ is presented as (33) while its amplitude $\mathbf{I}_{\text {pri2 }}$ and phase $\varphi_{2}$ are showed in (34)

$$
I_{\text {pri2 }}=\frac{V_{\text {pri }}}{Z_{\text {in } 2}}=\frac{V_{\text {pri }}}{\omega_{o} M_{2}\left(L_{22}+M_{2}\right)}\left(\omega_{o} M_{2} C_{22} R_{2 a c}+j L_{22}\right)
$$

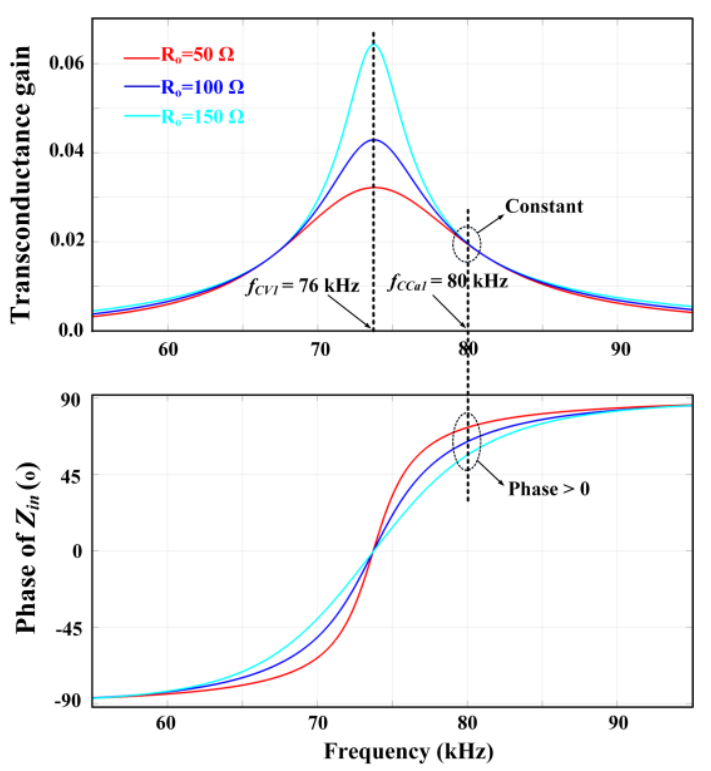

(a) $G_{i}$ and phase of $Z_{\text {in }}$ for Channel 1

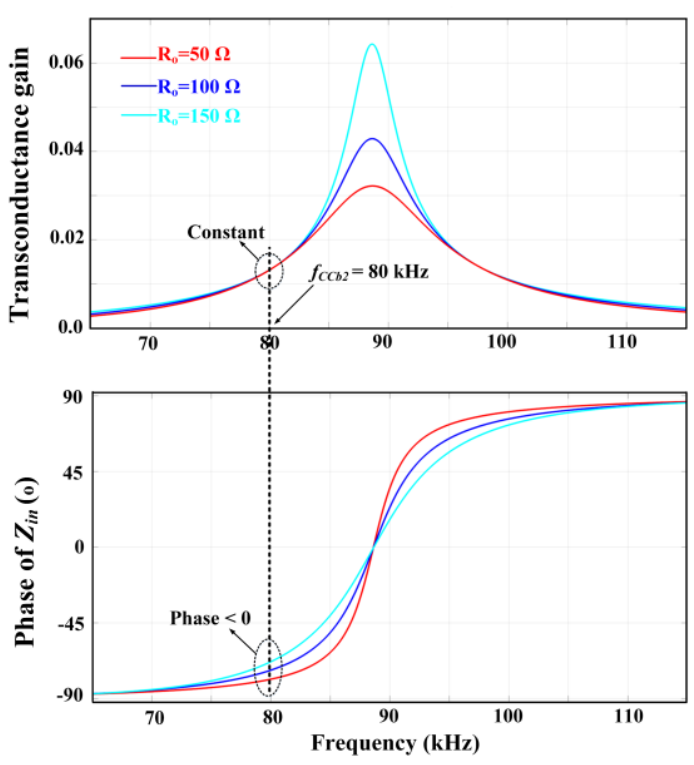

(b) $G_{i}$ and phase of $Z_{\text {in }}$ for Channel 2

Fig. 12 Implementing SP topology for the proposed multiple output system with $L_{11}=L_{12}=136 \mu \mathrm{H}, L_{21}=L_{22}=136 \mu \mathrm{H}, M_{1}=27 \mu \mathrm{H}, M_{2}=$ $27 \mu \mathrm{H}, C_{11}=C_{21}=36.31 \mathrm{nF}, C_{12}=C_{22}=24.34 \mathrm{nF}$.

$$
\left\{\begin{array}{c}
\mathbf{I}_{\text {pri2 }}=\frac{V_{\text {pri }} \sqrt{\left(\omega_{o} M_{2} C_{22} R_{2 a c}\right)^{2}+L_{22}^{2}}}{\omega_{o} M_{2}\left(L_{22}+M_{2}\right)} \\
\varphi_{2}=\tan ^{-1}\left(\frac{L_{22}}{\omega_{o} M_{2} C_{22} R_{2 a c}}\right)>0^{o}
\end{array}\right.
$$

At this point, we can realize that $\varphi_{1}$ is negative while $\varphi_{2}$ is positive, this is background so that we can minimize the phase $\varphi$ of $I_{\text {pri }}$. Obviously, $\varphi$ also depends on $\mathbf{I}_{\text {pri1 }}$ and $\mathbf{I}_{\text {pri2 }}$. The expression of $I_{\text {pri }}$ can be found as (35) with assumption of $L_{21}=L_{22}=L$ and $M_{1}=M_{2}=M$.

$$
I_{\text {pri }}=I_{\text {pri1 }}+I_{\text {pri2 }}=\frac{V_{\text {pri }}}{\omega_{o}\left(L^{2}-M^{2}\right)} *
$$

$\left\{\left[\omega_{o} L\left(C_{21} R_{1 a c}+C_{22} R_{2 a c}\right)+\omega_{o} M\left(C_{21} R_{1 a c}-C_{22} R_{2 a c}\right)\right]-j 2 L\right\}$

Finally, $\varphi$ can be calculated as: 
$\varphi$

$$
=\tan ^{-1}\left[\frac{-2 L}{\omega_{o} L\left(C_{21} R_{1 a c}+C_{22} R_{2 a c}\right)+\omega_{o} M\left(C_{21} R_{1 a c}-C_{22} R_{2 a c}\right)}\right]
$$

As shown in (36), $\varphi$ depends not only on imbalance load $C_{21} R_{1 a c}-C_{22} R_{2 a c}$ (if $C_{21}$ and $C_{22}$ are similar values) but also the value of $\left\{\omega_{o}, L, C_{21}, C_{22}, R_{1 a c}, R_{2 a c}\right\}$. In other words, if all resonant parameters of $\omega_{o}, L, C_{21}, C_{22}$ are assumed to keep constant, then $\varphi$ directly depends on $R_{1 a c}, R_{2 a c}$. Therefore, the conditions to minimum $\varphi$ should be considered in design procedure. Firstly, we can define the range of $R_{1 a c}, R_{2 a c}$ based on output load specification. Next, four variable of $\omega_{o}, L, C_{21}, C_{22}$ are taken into account to minimize $\varphi$. Obviously, they need to follows Eq. (25) for resonant condition of each channel.

Second point can be pointed out from Eq. (36) is that $\varphi$ is always negative phase meaning inverter current always goes ahead of inverter voltage. This feature can guarantee ZVS turn on for primary switches MOSFET.

Fig. 13 shows the variation of $\varphi$ depending on load of both channels $R_{1 a c}$ and $R_{2 a c}$. In general, when load resistance increases, then $|\varphi|$ reduces accordingly. As mentioned before, after determining the specific range of load $R_{1 a c}$ and $R_{2 a c}$, we can design other resonant components so that $|\varphi|$ can be minimized. In this work, as load resistance reaches to $250 \Omega$ at full load, then the value of $|\varphi|$ stands around $10^{\circ}$. At lower value of load resistance then $|\varphi|$ is higher but not exceed $23^{\circ}$. Experimental results in Fig. 24 are provided under different load conditions.

When number of output channels are more than two, we can still apply the concept and analysis of Option 2. To achieve it, all channels should be organized into different pairs in which a pair consists of two adjacent channels. For an even number of output channels $n$, then we have $m$ pairs $(m=n / 2)$. Each pair consists of two adjacent outputs which can be analysed and designed similarly by using Option 2 with SP topology. If $n$ is an odd number, then we also have $m$ pairs plus one last channel. Similarly for the first $m$ pairs, design procedure in this section can be used. For the last channel, it is required that the channel's resonant tank needs to operate at ZPA frequency. It means Option 1 needs to be used for the last channel. Therefore, we have two options:

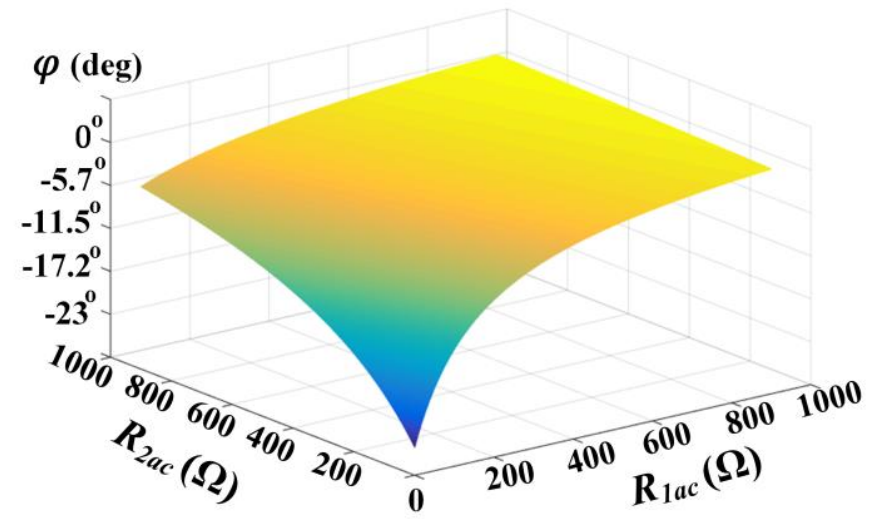

Fig. 13 Variation of $\varphi$ according different values of $R_{l a c}$ and $R_{2 a c}$ with $L_{11}=$ $L_{12}=136 \mu \mathrm{H}, L_{21}=L_{22}=136 \mu \mathrm{H}, M_{1}=27 \mu \mathrm{H}, M_{2}=27 \mu \mathrm{H}, C_{11}=$ $C_{21}=36.31 n F, C_{12}=C_{22}=24.34 n F$.
(1) Keep using SP topology to attain output voltage source. This channel will work around $\omega_{C V}$ in Eq. (26) with ZPA operation for SP resonant tank.

(2) Adopt SS topology to achieve output current source at ZPA resonant frequency.

Please note that Option 2 is proposed for applications requiring low cost and small circuit volume. Therefore, only simple topologies such as SP or SS should be considered here instead of double-sided LCL or LCC topologies.

On the other hand, Option 2 also can be applied for other one-order compensation topologies such as series-series (SS) when output voltage source is required. It is well-known that SS topology has three different resonant frequencies in which one is for output current source with ZPA operation and other two for output voltage sources with non-ZPA operation. Using SS topology diagram in Table II, then current-source frequency is $\omega_{o}=\frac{1}{\sqrt{L_{1} C_{1}}}=\frac{1}{\sqrt{L_{2} C_{2}}}$ and two voltage-source frequencies are $\omega_{1}=\frac{1}{\sqrt{\left(L_{1}-M\right) C_{1}}}=\frac{1}{\sqrt{\left(L_{2}-M\right) C_{2}}}$ and $\omega_{2}=$ $\frac{1}{\sqrt{\left(L_{1}+M\right) C_{1}}}=\frac{1}{\sqrt{\left(L_{2}+M\right) C_{2}}}$, respectively. For two voltage source frequencies, input impedance of SS has positive phase at $\omega_{1}$ and negative phase at $\omega_{2}$. Applying the same concept in this session for two-channel system using SS topology, Channel 1 adopts $\omega_{1}$ while Channel 2 adopts lower frequency $\omega_{2}$. The phase cancellation between two channels results in almost ZPA operation for primary inverter of two-channel with SS topology.

\section{Dynamic operation and closed-loop control}

In this section, the system's dynamic operation is carried on and analysed as voltage or current in transition period can exceed their limited values sometimes and may destroy components in the real scenario. To simplify, all analysis here is conducted based on above option I with LCC-LCC topology. To examine system under transition time, a situation is assumed when one car is charging at full load, and the other car suddenly arrives and connects to the system to charge at full load as well. Firstly, simulation with open-loop control of two channels is conducted at rated power of $1.5 \mathrm{~kW}$ for each channel as shown in Fig. 14. When $S_{a 2}$ switches from $\mathrm{OFF}$ to $\mathrm{ON}$ at 0.01 second, system enables to charge load 2 immediately. As we can see from Fig. 15, then input current $I_{\text {pri1 }}$ of Channel 1 is still stable while $I_{\text {pri2 }}$ suddenly increases to rated value after several periodic oscillations. Maximum peak-value of $I_{\text {pri2 }}$ is $30 \mathrm{~A}$ during transition period as compared to normal value of $18.5 \mathrm{~A}$. In output side, $V_{o 1}$ is constant and stable at $190 \mathrm{~V}$ while $V_{o 2}$ starts to rise from zero and reaches maximum value within 0.06 seconds. Simulation results indicates that the proposed system performs well under dynamic situations even without closed-loop control. Simulations of several similar dynamic operations also provide the same conclusion. 


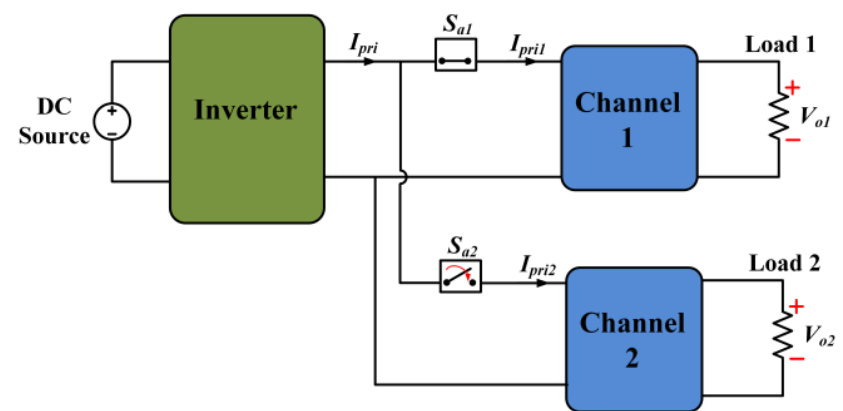

Fig. 14. An example of system's dynamic operation. Switch $S_{a 1}$ remains ON over the whole period while $S_{a 2}$ changes from OFF to ON when Channel 2 is activated.

Fig. 16 shows the relationship between mutual inductance $M$ and variation of misalignment $D_{1}$ or air-gap $D_{2}$ for one channel only. Fig. 16a shows values of $M$ when $D_{2}=15 \mathrm{~cm}$ while there is no misalignment $\left(D_{1}=0\right)$ in results showed in Fig. 16b. It is clearly seen that by both simulated and experimental results that, $M$ drops quickly when either $D_{1}$ or $D_{2}$ increases. Therefore, output current $I_{o}$ reduces accordingly as $M$ drops, which is depicted in Fig. 17. Fig 17a illustrates variation of $I_{o}$ when air-gap reaches $15 \mathrm{~cm}$ and misalignment occurs from 0 to $10 \mathrm{~cm}$ while Fig $17 . \mathrm{b}$ shows variation of $I_{o}$ under variation of air-gap in range from $10 \mathrm{~cm}$ to $20 \mathrm{~cm}$. As a result, closed-loop control is required to maintain constant charging current or voltage under the variation of mutual inductance or load conditions. The buckboost converter is added in between rectifier and load in secondary side, which plays a role as a DC-DC regulator for each channel as shown in Fig. 18. In CC mode, the regulator keeps constant the charging current $I_{o 1}, I_{o 2}$ when $M_{11}$ or $M_{12}$ varies. If we assume that air-gap is constant at $15 \mathrm{~cm}$ and only misalignment shows up, then $I_{o 1}$ or $I_{o 2}$ drops, therefore, the regulator works normally in boost mode to increase output voltage so that maintaining the desirable value of current. In $\mathrm{CV}$ mode, regulator has two main tasks. The first task is to step down output voltage $V_{o 1}$ and $V_{o 2}$ to normal values under the increase of load impedance. Second task is to stabilize $V_{o l}$ and $V_{o 2}$ under variation of $M_{11}$ or $M_{12}$. Regulator can operate as either buck or boost converter during $\mathrm{CV}$ charging mode. The duty cycles $d_{51}$ and $d_{61}$ of Channel 1 and $d_{52}$ and $d_{62}$ of Channel 2 are varied depending mode charge and mutual inductances. Detailed control procedure for one channel is depicted in the flowchart in Fig. 19. As implementation of these regulators is well-known, then authors do not go into detail and only the main points are briefly described.

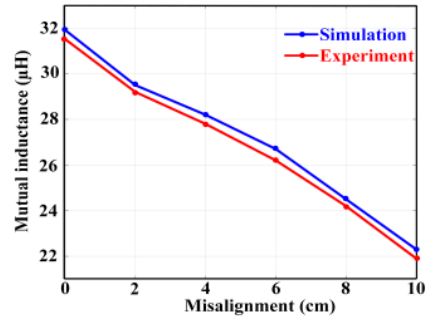

(a) Misalignments (air-gap $=15 \mathrm{~cm}$ )

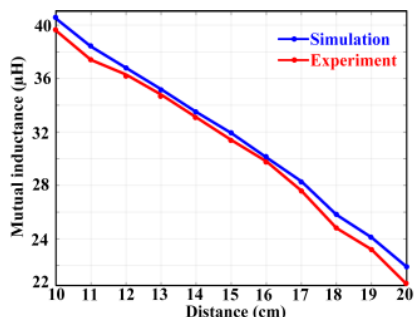

(b) Different air-gap

Fig. 16 Variation of mutual inductance $M$ versus
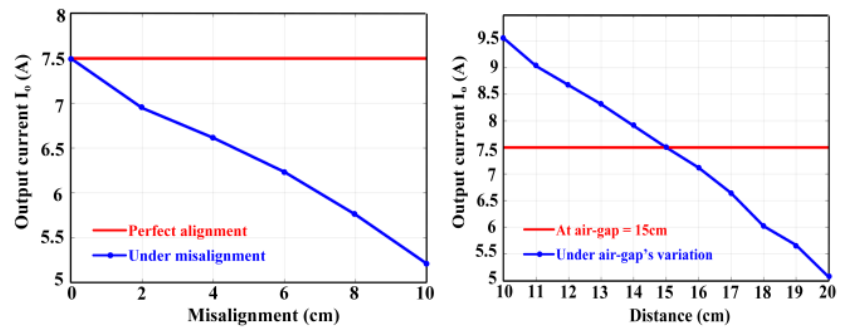

(a) Misalignment

(b) Different air-gap (no misalignment)

Fig. 17 Variation of output current $I_{o}$ versus

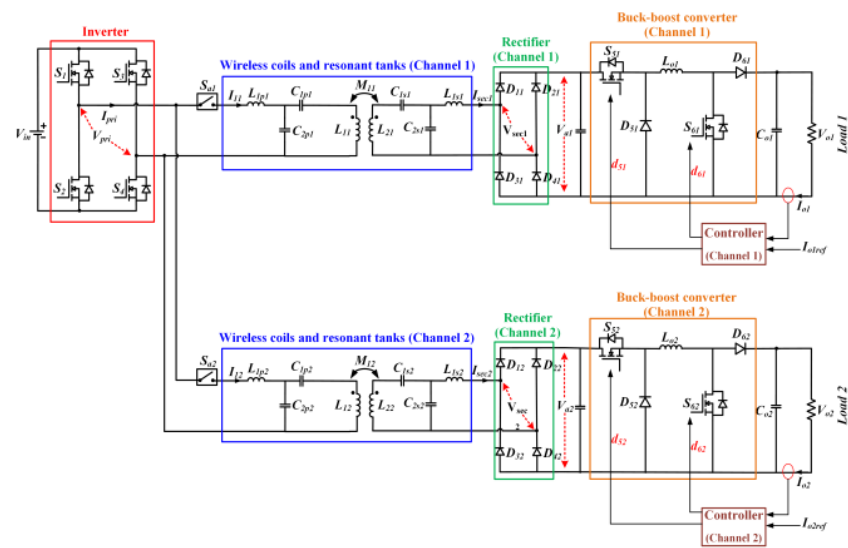

Fig. 18 The buck-boost converter uses for regulating the output current and voltage in Option 1.

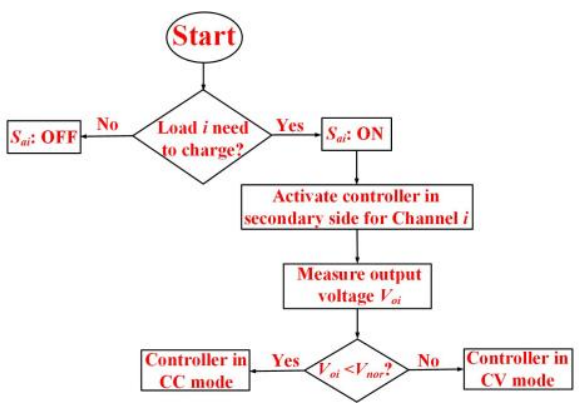

Fig. 19 The control procedure for one channel in the multi-output

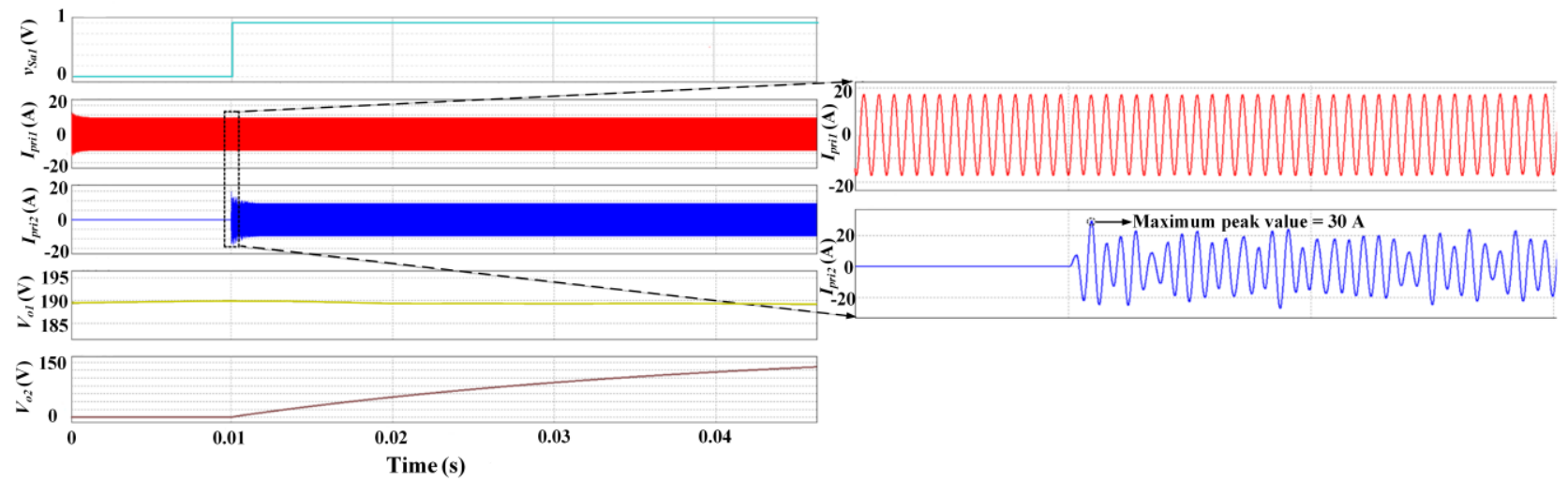

Fig 15. The key waveforms in transition operation for LCC-LCC topology with parameters are given in Table III and $M_{11}=M_{12}=32.25 \mu \mathrm{H}$ 


\section{EXPERIMENTAL RESULTS}

To validate the feasibility of the proposed system, a prototype of two-channel IPT charger is built up and tested. Option 1 is verified with LCC-LCC topology as shown in Fig. 18 while option 2 is examined with SP topology as shown in Fig. 11. Our primary purpose is to verify ZPA operation of primary inverter for both options, therefore only open-loop test results were reported. The rated power for two-channel system is $1.5 \mathrm{~kW}$ for Option 1 and $1 \mathrm{~kW}$ for Option 2. The closed-loop control for misalignment has been verified by simulation and will be showed up in our future publications as it is not our main goal in this work.

TABLE III. SPECIFICATION AND PARAMETERS FOR ONE CHANNEL OF IPT SYSTEM

\begin{tabular}{|c|c|c|c|}
\hline & Parameter & Symbol & Value \\
\hline \multirow[t]{7}{*}{ For both options } & Input Voltage & $V_{\text {in }}$ & $180-220 \mathrm{~V}$ \\
\hline & Rated Output Current & $I_{o}$ & $4 \mathrm{~A}$ \\
\hline & $\begin{array}{l}\text { Rated Output Power } \\
\text { (single channel only) }\end{array}$ & $P_{o}$ & $750 \mathrm{~W}$ \\
\hline & Self-inductance & $L_{1}, L_{2}$ & $133 \mu \mathrm{H}$ \\
\hline & $\begin{array}{l}\text { Magnetizing } \\
\text { inductance }\end{array}$ & $M$ & $\begin{array}{c}22-37.8 \\
\mu \mathrm{H}\end{array}$ \\
\hline & Normal air-gap & $D$ & $15 \mathrm{~cm}$ \\
\hline & Switching frequency & $f_{o}$ & $80 \mathrm{kHz}$ \\
\hline \multirow[t]{3}{*}{ Option 1 only } & Additional inductor & $L_{l p}, L_{2 p}$ & $47.5 \mu \mathrm{H}$ \\
\hline & Series Capacitors & $C_{l p}, C_{l s}$ & $44 \mathrm{nF}$ \\
\hline & Parallel Capacitors & $C_{2 p}, C_{2 s}$ & $88 \mathrm{nF}$ \\
\hline \multirow[t]{2}{*}{ Option 2 only } & Primary capacitor & $C_{11}, C_{21}$ & $39 \mathrm{nF}$ \\
\hline & Secondary capacitor & $C_{12}, C_{22}$ & $24.34 \mathrm{nF}$ \\
\hline
\end{tabular}

Fig. 20a illustrates experimental setup of wireless coils prototype of two-channel system for both Options 1 and 2 . System specification and parameters of resonant components for each channel are given in Table III. A pair of 12-turn Litz wire $36 \mathrm{AWG}$ is constructed with ferrite core for wireless coils as showed in Fig. 2a. The air-gap between the transmitter and receiver coil is set to $150 \mathrm{~mm}$ for each channel. The distance from the center of coil's channel 1 to coil's channel 2 is chosen to be 2 meters in the setup to neglect the cross-coupling problem between two channels. Primary full-bridge inverter for all channels adopts SicMOSFET C2M0080120 from Cree Inc. as shown in Fig. 20b while SiC- Schottky-diode HFA50PA60 is used for the rectifier of each channel. Due to the lower equivalent series resistance and higher current carrying capability, polypropylene film capacitors are used for the resonant capacitors in the testing. The switching frequency of $80 \mathrm{kHz}$ is used for testing. In the real scenario, when the car is parked and ready to be charged, then user can use an app installed on the phone to send a signal to primary side to turn $\mathrm{ON}$ the contactor $S_{a i}$. It also required a wireless communication such as Bluetooth to transfer the controlled signal and a controller in primary side to active or deactivate a specific channel. As contactors can be easily controlled by a DC source, therefore the control procedure is not difficult to implement. In this work, to implement $S_{a 1}$ and $S_{a 2}$, contactor 3RT1026 from Siemens and a switch are adopted to manually control contactor for simplicity as shown in Fig. 20c. More works using wireless communication and automatic control for contactors will be investigated in our future researches.
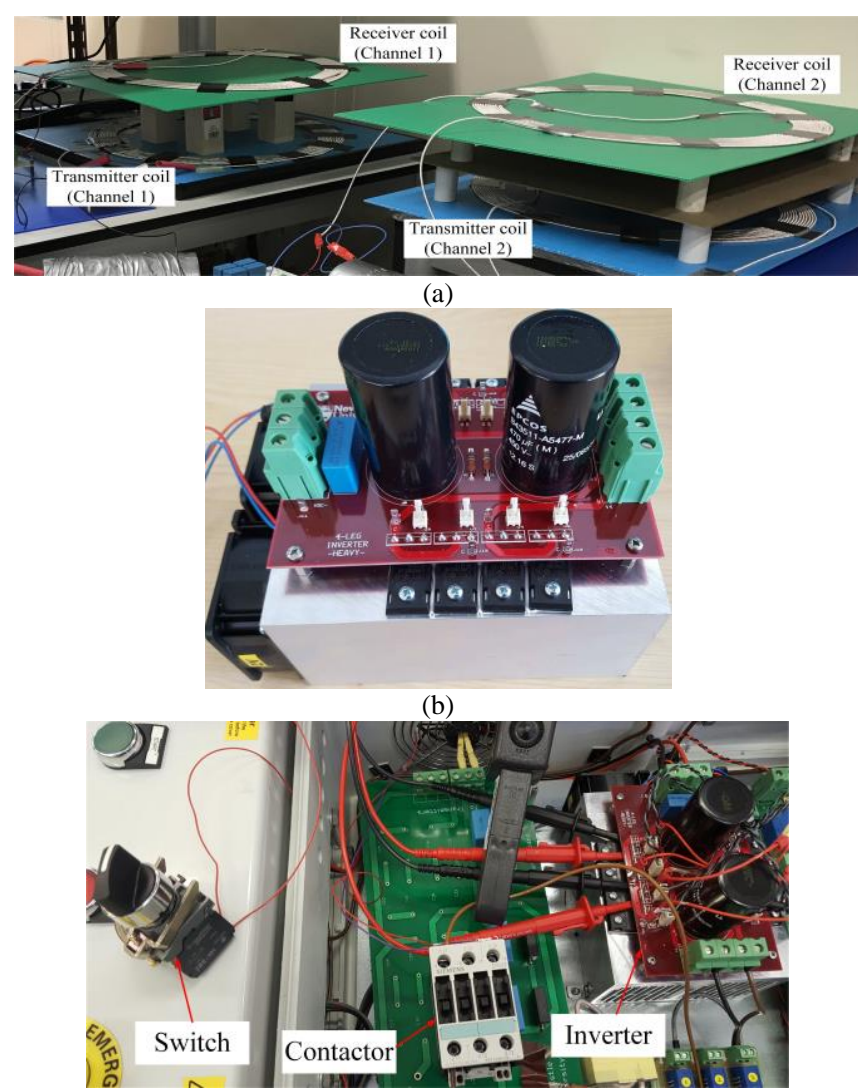

(c)

Fig. 20 (a) Prototype of IPT coils for two-channel multiple output system (b) Single inverter used in testing (c) Contactor circuit to switch an output channel

Option 1's performance at different load conditions is firstly presented. The following results illustrate three different cases. The first case is of $100 \%$ load for both channels with $R_{L 1}=R_{L 2}=47 \Omega$. The second case is of $100 \%$ load for the channel 1 and $50 \%$ load for channel 2 . The other case is of $10 \%$ load for channel 1 and $100 \%$ load for channel 2. The load condition of $100 \%$ indicates $170 \mathrm{~V}$ of battery's voltage while this number is $85 \mathrm{~V}$ and $17 \mathrm{~V}$ under the condition of $50 \%$ and $10 \%$ load. In all cases, a charging current of $3.5 \mathrm{~A}$ is expected to keep the same for both channels. According to results, we examine the effect of load variation in channel 2 to channel 1 as well as channel 1 to channel 2. It is also required that the charger needs to supply an accurate power for each battery at the different time.

The main operation waveforms under different load conditions are provided in Fig. 21-23. The waveforms of voltage $V_{d s 1}$ and current $I_{d s l}$ on primary inverter switch $S_{l}$ are depicted in Fig. 21(a) and Fig. 22(a). As clearly seen that $S_{l}$ is always turned ON under ZVS condition, and turned OFF under nearly Zero Current Switching (ZCS) condition, reducing switching losses for the inverter circuit. With $100 \%$ load of both Channel 1 and 2, waveforms of voltage after inverter stage $V_{p r i}$ and input currents of each channel $I_{11}$ and 
$I_{12}$ are presented in Fig. 21(b) and Fig. 21(c). Similar waveforms are shown in Fig. 22(b) and Fig.22(c) with 100\% load of Channel 1 and 50\% load of Channel 2. According to that, the phase-shift between $V_{p r i}$ and input currents $\left(I_{11}\right.$ and $I_{12}$ ) are close to zero with each other regardless of load conditions, verifying that the compensation tank has eliminated most of the reactive power in both cases. The primary input current $I_{11}$ of the channel 1 is equal to channel 2 $I_{12}$ under the same load condition while $I_{11}$ is greater than $I_{12}$ when $R_{L 1}=2 R_{L 2}$. Even when the load of channel 2 drops to $10 \%$ while channel 1 remains $100 \%$, the phase-shift between $V_{p r i}$ and $I_{11}$ or $I_{12}$ still keep nearly the same as previous case as shown in Fig. 23. Obviously, $I_{12}$ value is greater 10 times than $I_{11}$ because of load variation. From above results we can conclude that ZPA operation is realized for primary inverter with different range of output load.

Fig. 21 (d)-(e) and Fig. 22(d)-(e) show the main waveforms in the secondary side. The secondary side currents $I_{\text {sec }}$ and $I_{s e c 2}$ are nearly the same in both cases of load conditions, which reflect the $\mathrm{CC}$ mode operation. For first case, when load conditions are the same, the voltage before rectifier of the channel $1 V_{\text {secl }}$ is nearly the same of the channel $2 V_{\sec 2}$ as depicted in Fig. 21(d) and Fig. 21(e). When channel 1 requires $100 \%$ load and channel 2 requires $50 \%$ load in the second case, $V_{\sec 2}$ is a half of $V_{\text {secl }}$ as shown in Fig. 22(d) and Fig. 22(e), because of $R_{L 1}=2 R_{L 2}$.

The shape of both primary and secondary waveforms is nearly kept the same under load variation. The change of the magnitude of $I_{12}$ and $V_{\text {sec } 2}$ reflect the drop of output power on channel 2 while all waveforms of Channel 1 remain of both shape and magnitude. The similar thing happens when load of channel 1 drops 10 times while channel 2 remains at rated as shown in Fig. 23. They indicate that operation of each channel is almost independent and the cross-regulation problem can be neglected in the proposed system. As long as we can guarantee there is no cross-coupling between IPT coils, cross-regulation problem will not be a big problem.

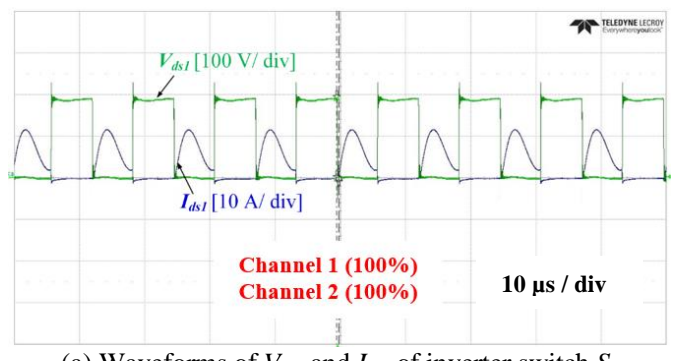

(a) Waveforms of $V_{d s l}$ and $I_{d s l}$ of inverter switch $S_{I}$

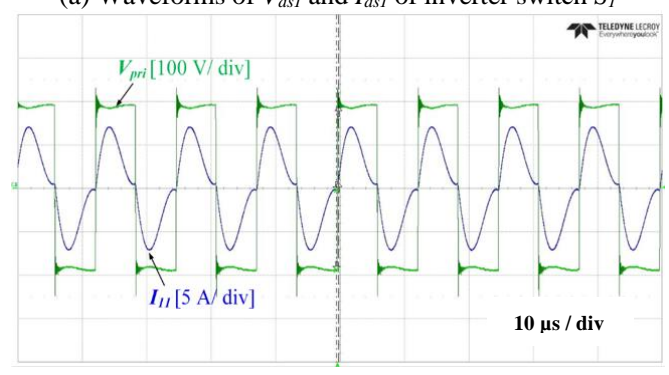

(b) Waveforms of $V_{p r i}$ and $I_{11}$ of channel 1

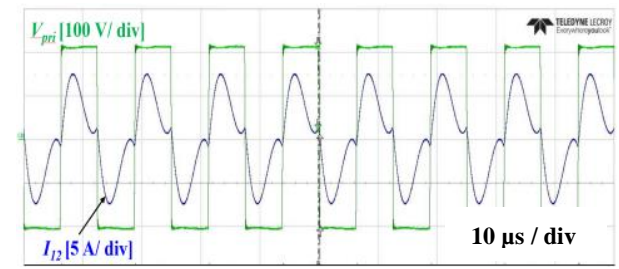

(c) Waveforms of $V_{p r i}$ and $I_{12}$ of channel 2

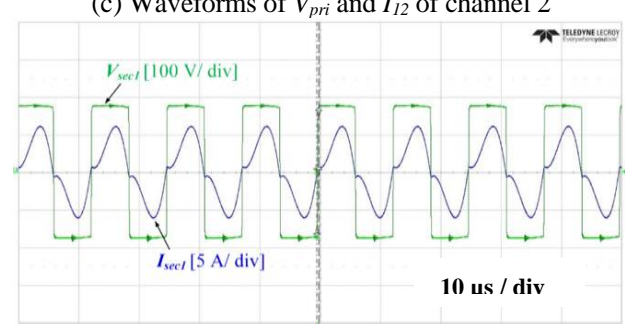

(d) Waveforms of $V_{\text {secl }}$ and $I_{\text {secl }}$ of channel 1

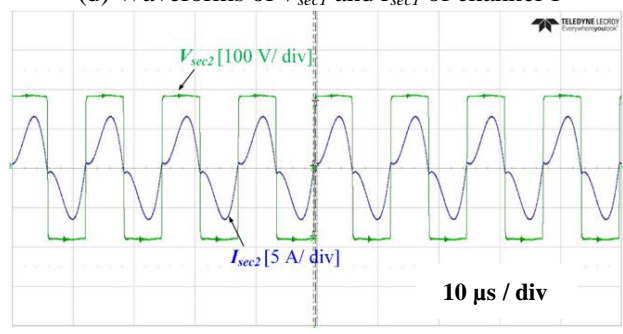

(e) Waveforms of $V_{s e c 2}$ and $I_{s e c 2}$ of channel 2

Fig. 21. Experimental waveforms when the load condition of $100 \%$ for channel 1 and $100 \%$ for channel 2 .

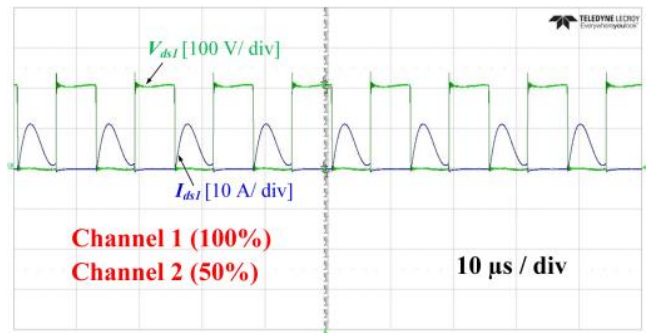

(a) Waveforms of $V_{d s l}$ and $I_{d s l}$ of inverter switch $S_{l}$

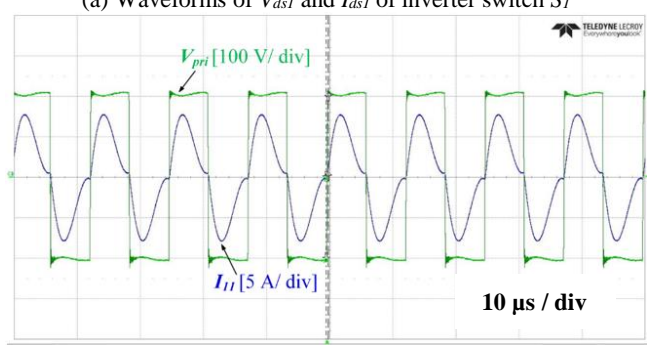

(b) Waveforms of $V_{p r i}$ and $I_{l l}$ of channel 1

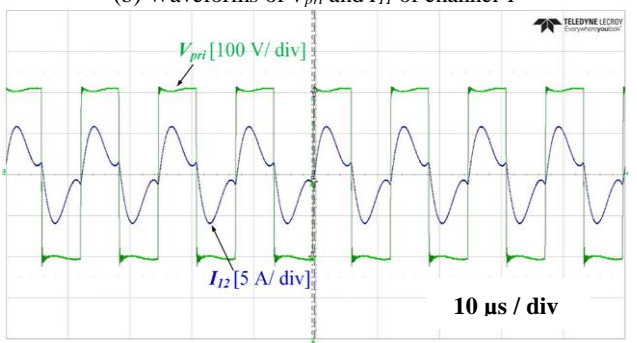

(c) Waveforms of $V_{p r i}$ and $I_{12}$ of channel 2

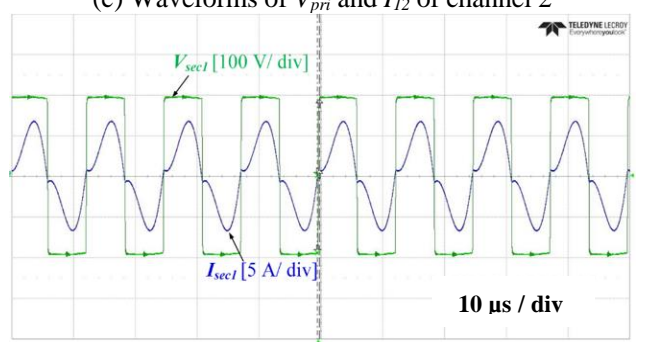


(d) Waveforms of $V_{\text {secl }}$ and $I_{\text {secl }}$ of channel 1

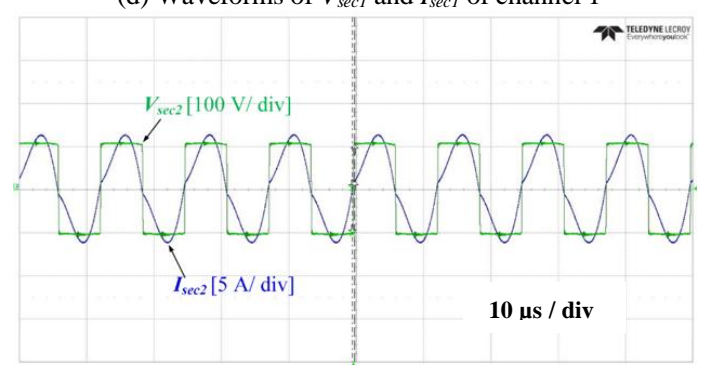

(e) Waveforms of $V_{\sec 2}$ and $I_{\sec 2}$ of channel 2

Fig. 22. Experimental waveforms when the load condition of $100 \%$ for channel 1 and $50 \%$ for channel 2 .

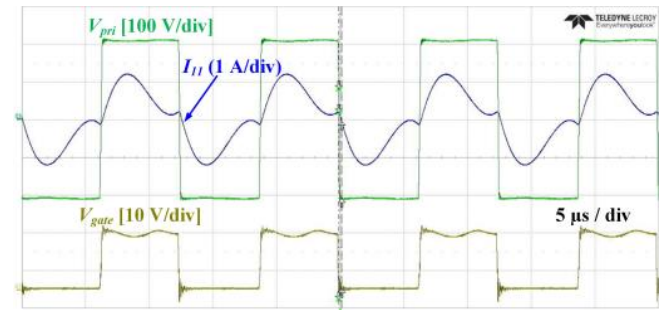

(a) Waveforms of $V_{p r i}$ and $I_{11}$ of channel 1

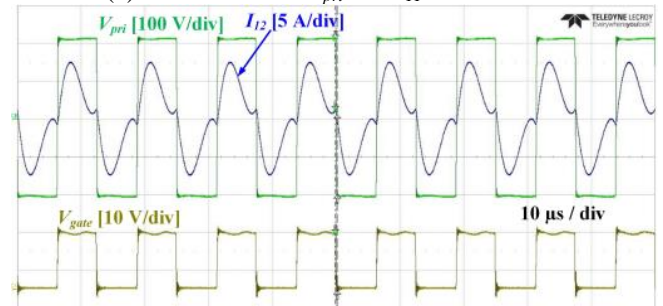

(b) Waveforms of $V_{p r i}$ and $I_{12}$ of channel 2

Fig. 23. Primary side waveforms when the load condition of $10 \%$ for channel 1 and $100 \%$ for channel 2.

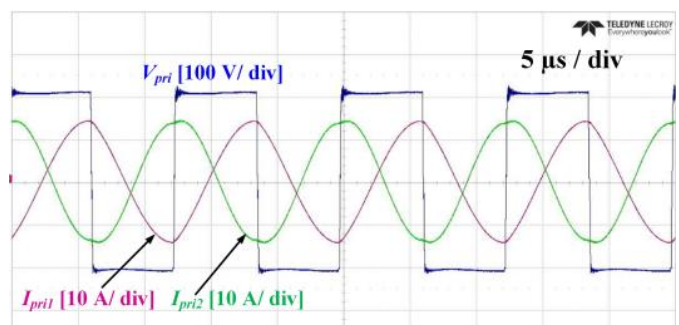

(a) Waveforms of $V_{p r i}, I_{p r i 1}$ and $I_{p r i 2}$ at $100 \%$ rated load.

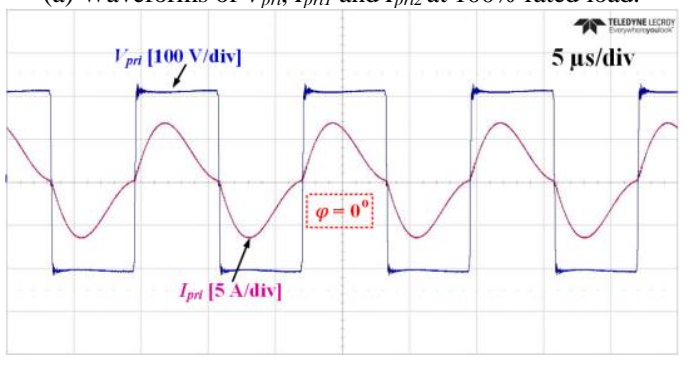

(b) Waveforms of $V_{p r i}$ and $I_{p r i}$ at $100 \%$ rated load.

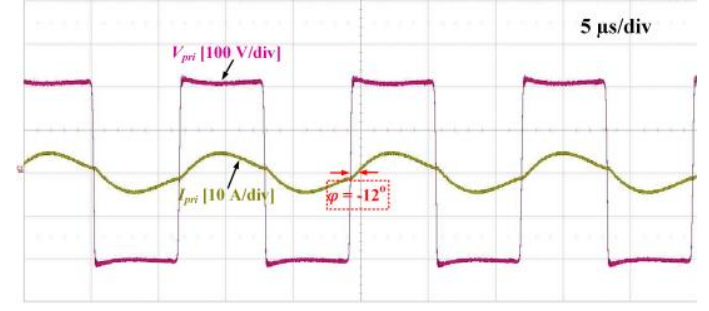

(c) Waveforms of $V_{p r i}$ and $I_{p r i}$ at $60 \%$ rated load

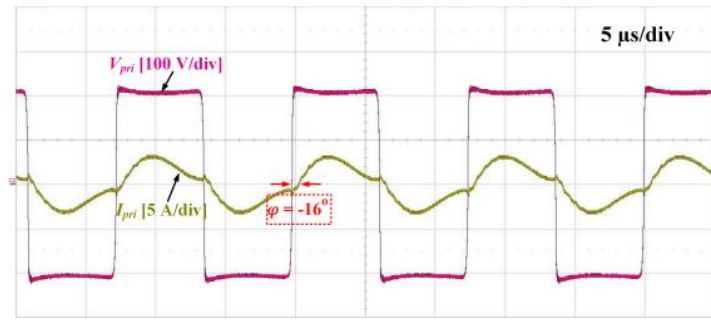

(d) Waveforms of $V_{p r i}$ and $I_{p r i}$ at $10 \%$ rated load

Fig. 24. Experimental waveforms for option 2 operation under different load conditions: (a) and (b) at total rated power of $1 \mathrm{~kW}$ with $R_{1}=R_{2}=250 \Omega$, (c) with $R_{l}=250 \Omega$ and $R_{2}=25 \Omega$ (60\% of rated power), (d) with $R_{l}=R_{2}=25 \Omega$ ( $10 \%$ of rated power). The tests were conducted at: $L_{11}=L_{12}=$ $133.5 \mu \mathrm{H}, L_{21}=L_{22}=134.3 \mu \mathrm{H}, M_{1}=27 \mu \mathrm{H}, M_{2}=23.3 \mu \mathrm{H}, C_{11}=$ $C_{21}=39 \mathrm{nF}, C_{12}=C_{22}=24.34 \mathrm{nF}$.

Fig. 24 presents the main waveforms of option 2 at different load conditions. The tests were conducted from $10 \%$ to $100 \%$ total rated output power. Fig. 24 (a) and (b) show the key waveforms of $V_{p r i}, I_{p r i l}, I_{p r i 2}$ and $I_{p r i}$ at rated power of $1 \mathrm{~kW}$ with load resistances of both channels are $250 \Omega$. It is clearly showed that the difference phase $\varphi$ reaches nearly zero and ZPA operation can be achieved as a result. When the total load and load resistances reduced then $\varphi$ decreases as well. Starting from $60 \%$ of rated load with $R_{1}=250 \Omega$ and $R_{2}=25 \Omega$ as depicted in Fig. 24 (c), then $\varphi$ reduces $-12^{\circ}$. When the total load power goes down to lowest value of $10 \%$, then $\varphi$ reduces to $-16^{\circ}$ as shown in Fig. 24(d). As the slight mismatch between simulation and experiment parameter, therefore, experimental values of $\varphi$ cannot meet exactly with simulation values in Fig. 13. However, the errors of $\varphi$ are quite small, then we can conclude that experimental results verify analysis in Section III. C (as depicted by Eq. 36) and ZPA operation can be nearly achieved for inverter under a full range of load conditions. Please noted that due to not operating in ZPA region, therefore, the stresses of currents $I_{p r i 1}$ and $I_{p r i 2}$ on resonant capacitors and coil are considerably large as compared to the inverter current $I_{p r i}$.

The measured voltage and current stresses on $S_{a l}$ during transition period is showed in Fig. 25 when switching contactor from OFF to ON state. When $S_{a 1}$ turns OFF (no required output), then the current through contactor $I_{S a l}$ is zero as open-circuit. Only voltage stress $V_{S a l}$ applies on $S_{a l}$ with voltage value is same as inverter output voltage. After $S_{a l}$ turns ON then voltage on contactor is zero and input current go through $S_{a l}$ to supply for primary resonant tank. The current through contactor $S_{a l}$ is equal to input current $I_{1 l}$. It is noted that there is no switching losses for $S_{a l}$ during transition time and conduction losses are reported only as $1-3 \mathrm{~W}$ in contactor's datasheet.

In the worst case if $S_{a i}$ gets failure and turns OFF while channel $i$ is charged. Consequently, the corresponding channel is out of system and the output battery no longer receives power while other channels still work in normal operation. There will not be any serious damage to both IPT charger and users under this scenario. To minimize the possibility of failure, contactors are selected to implement $S_{a i}$ instead of switching devices (i.e. IGBT or MOSFET) in this work as contactors offer higher reliability as well as simpler and easier to build the control circuit. 


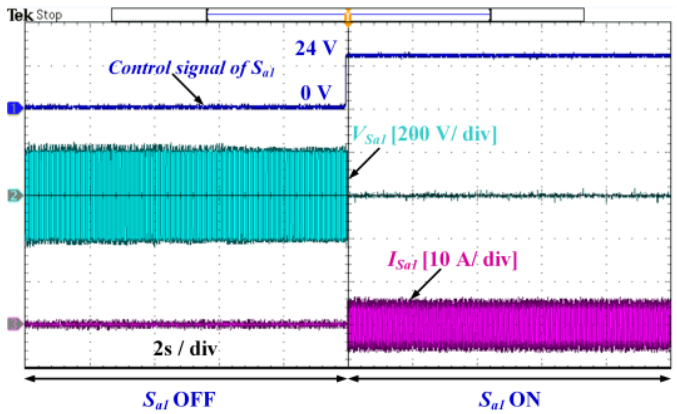

(a)

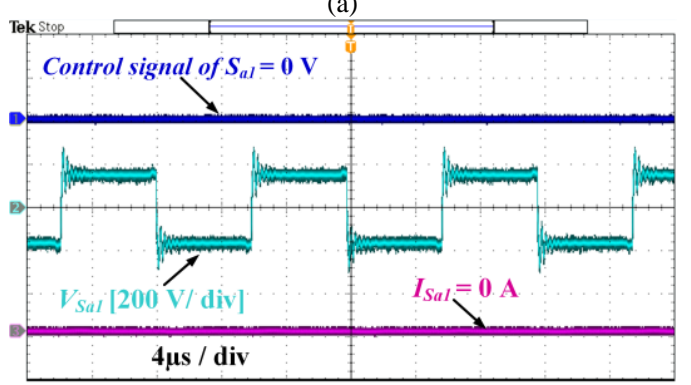

(b)

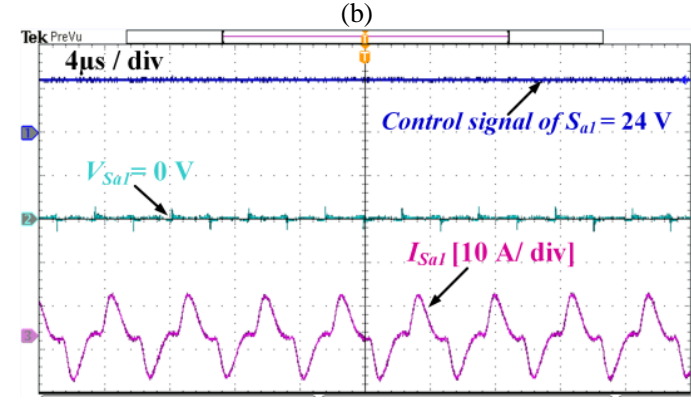

(c)

Fig. 25. (a) The measured stresses of voltage and current on $S_{a l}$ during transition time and Zoom in of waveforms when (b) $S_{a l}$ OFF, (c) $S_{a l}$ ON

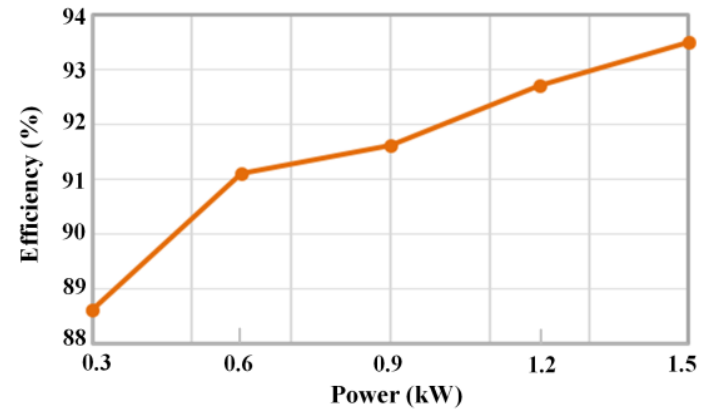

(a)

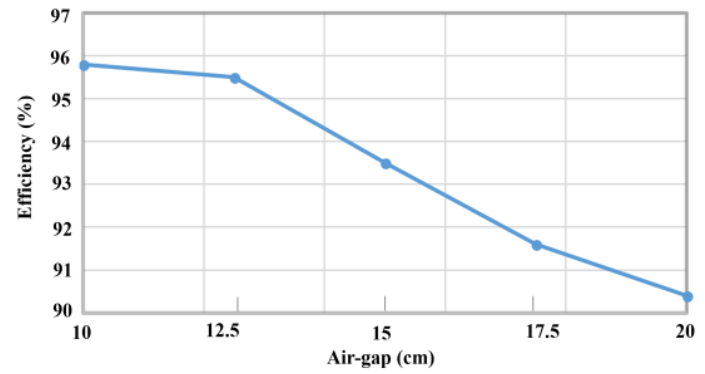

(b)

Fig. 26 Efficiency of Option 1 versus (a) different output powers (b) different air-gap

Experiments of Option 1 at different conditions of load and air-gap were also conducted to measure and evaluate efficiency performance, which are presented in Fig. 26. When output load increases from 0.3 to $1.5 \mathrm{~kW}$, then efficiency rises from 88.6 to $93.5 \%$, respectively. All data in Fig. 26a were measured at $15 \mathrm{~cm}$ of air-gap and no misalignment. We also tested at different air-gap while keeping the same load $\left(R_{I}=\right.$
$R_{2}=47 \Omega$ ). Results are depicted in Fig. 26b in which maximum efficiency got $95.8 \%$ at air-gap $=10 \mathrm{~cm}$. Efficiency gradually reduces to $90.4 \%$ when air-gap increases from 10 to $20 \mathrm{~cm}$, respectively. At normal working conditions of $15 \mathrm{~cm}$ of air-gap and $1.5 \mathrm{~kW}$ of output power, efficiency reaches $93.5 \%$.

For Option 2, as selection of all capacitors $\left(C_{11}, C_{12}, C_{21}\right.$ and $C_{22}$ ) depends on coupling factors between two coils, then we only measured efficiency when air-gap equals to $15 \mathrm{~cm}$ for both channels for simplicity. Fig. 27 shows efficiency values when total output power varies from 0.2 to $1 \mathrm{~kW}$. Due to higher currents through resonant tank causing higher conduction losses, then efficiency of Option 2 is slightly lower than Option 1 with the same amount of output power.

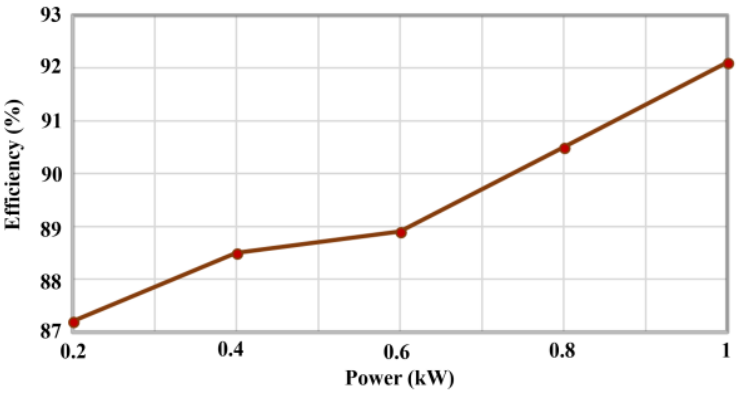

Fig. 27 Efficiency of Option 2 versus different output powers

\section{DISCUSSION AND CONCLUSION}

This paper suggests a new concept to design and implement a multiple output IPT charger consisting of several output channels for EV's application. The proposed system can independently charge several output batteries of EVs at the same time by adopting only one full bridge inverter at the primary side. Two possible configurations of IPT coil for proposed multiple output system are suggested and compared to simulation results. Minimum distance between two channel's coils is selected to overcome from the crossregulation problem. A family of IPT load-independent current topologies is examined and conditions to achieve load independent current and ZPA of primary tank is fully given in this paper. Two possible options to realize the proposed multiple output charger are suggested, analyzed and compared together. One option is to operate each channel's compensation tank at exact ZPA frequencies. The other option is to let one output channel working in inductive region of its input impedance and the others working in capacitive region. The main purpose is to achieve ZPA operation for primary inverter and also provide different solutions for different applications, in which requirements are not the same. A twooutput-channel prototype is built and tested under different load conditions to validate the validity of the proposed system with both above operational options. The experimental results illustrated with double-sided LCC topology for option 1 and SP topology for option 2 .

As mentioned before, both proposed options 1 and 2 are able to achieve ZPA operation for primary inverter. Option 1 is provided for topologies, which can achieve ZPA operation even for single output channel. While option 2 is proposed for applications requiring the less number of resonant components and not achieving ZPA for single output. Option 1 with examples by double-sided LCC topology can easily attain ZPA operation for all load conditions while option 2 with SP topology ideally achieve around a specific range of load. 
However, the phase-shift different of output inverter current and voltage is not too much and can be considered acceptable. In conclusion, option 1 can be used widely if the application does not need to meet any special requirements such as minimum number of component or space for installation. With applications which must meet above requirements, then option 2 should be considered.

If we go into comparison between conventional and the proposed configuration, then several following criterions should be taken into considerations. They include total implementing-cost, rating on primary inverter, space for installation, reliability as well as complexity. The proposed system outweighs in terms of implementing-cost, space for installation and complexity with the main reason from adopting only one inverter as mentioned before. However, system's reliability of the proposed one is reduced and stresses of voltage and current on the central inverter are much higher than string inverters in cases of conventional system. For some unexpected reasons, if central inverter stops working, then no power will provide to all output loads. Therefore, more attention should be paid for design and protection of central inverter in case of the proposed system.

\section{REFERENCES}

[1] M. Yilmaz and P. T. Krein, "Review of Battery Charger Topologies, Charging Power Levels, and Infrastructure for Plug-In Electric and Hybrid Vehicles," in IEEE Trans. Power Electron., vol. 28, no. 5, pp. 2151 - 2169, Aug. 2012.

[2] S. Li, and C. C. Mi, "Wireless Power Transfer for Electric Vehicle Applications" in IEEE J. Emerg. Sel. Topic on Power Electron., vol. 3 , no. 1, pp. 4-17, Mar. 2015.

[3] J. M. Miller, P.T. Jones, J-M. Li and O. C. Onar "ORNL Experience and Challenges Facing Dynamic Wireless Power Charging of EV's," IEEE Power Electron. Mag., vol. 15, no. 2, pp. 40-53, May. 2015.

[4] C.W. Wang, et al. "Design Considerations for a Contactless Electric Vehicle Battery," IEEE Trans. Power Electron., vol. 52, no. 5, Oct. 2005.

[5] X. Qu, H. Han, S. C. Wong, C. K. Tse and W. Chen. "Hybrid IPT Topologies with Constant-Current or Constant-Voltage Output for Battery Charging Applications," IEEE Trans. Power Electron, vol. 1, no. 1, pp. 6329 - 6337, Jan. 2015

[6] C.-S. Wang, G. A. Covic, and O. H. Stielau, "Investigating an LCL load resonant inverter for inductive power transfer applications," IEEE Trans. Power Electron., vol. 19, no. 4, pp. 995-1002, Jul. 2004.

[7] U. K. Madawala and D. J. Thrimawithana, "A bidirectional inductive power interface for electric vehicles in V2G systems," IEEE Trans. Ind. Electron., vol. 58, no. 10, pp. 4789-4796, Oct. 2011.

[8] N. A. Keeling, G. A. Covic, and J. T. Boys, "A unity-power-factor IPT pickup for high-power applications," IEEE Trans. Ind. Electron., vol. 57, no. 2 pp. 744-751, Feb. 2010.

[9] Z. Pantic, B. Sanzhong, and S. Lukic, "ZCS LCC-compensated resonant inverter for inductive-power-transfer application," IEEE Trans. Ind. Electron., vol. 58, no. 8, pp. 3500-3510, Aug. 2011.

[10] S. Li, W. Li, J. Deng, T. D. Nguyen and C. C. Mi, "A Double-Sided LCC compensation Network and Its Tuning Method for Wireless Power Transfer," IEEE Trans. Veh. Technol., vol. 64, no. 6, pp. 2261 -2273 , Jun. 2015.

[11] M. Budhia, J. Boy, G. Covic and C. Y. Huang, "Development of a single-side Flux Magnetic Coupler for Electric Vehicle IPT Charging Systems" IEEE Trans. Ind. Electron, vol. 60, no. 1, pp. 318 - 328, Jan. 2013.

[12] Y. Nagatsuka, N. Ehara, Y. Kaneko, S. Abe, T. Yasuda, "Compact contactless power transfer system for electric vehicles", Proc. IPEC, pp. 807-813, 2010.

[13] Mickel Budhia, John Boy and Grant Covic, "Design and Optimization of Circular Magnetic Structures for Lumped Inductive Power Transfer Systems", Power Electronics, IEEE Transactions on, Vol.26, No 11, 2011.

[14] W. Zhang, J. White, R. Malhan, and C. C. Mi, "Loosely coupled transformer coil design to minimize emf radiation in concerned areas," IEEE Trans. Veh. Technol., vol. 65, no. 6, pp. 4779-4789, Jun. 2016.
[15] W. X. Zhong, C. Zhang, X. Liu and S. Y. R. Hui, "A Methodology for Making a Three-Coil Wireless Power Transfer System More Energy Efficient Than a Two-Coil Counterpart for Extended Transfer Distance," IEEE Trans. Power Electron., , vol. 30, no.2, pp.933-942, Feb. 2015.

[16] S. Moon, B.C. Kim, S.Y. Cho, C.H. Ahn, and G.W. Moon, "Analysis and design of a wireless power transfer system with an intermediate coil for high efficiency," IEEE Trans. Ind. Electron., vol. 61, no. 11, pp. 5861-5870, Nov. 2014

[17] D. H. Tran, V. B. Vu and W. J. Choi, "Design of a High Efficiency Wireless Power Transfer System with Intermediate Coils for the Onboard Chargers of Electric Vehicles," IEEE Trans. Power Electronics, vol. 33, no. 1, pp. 175-187, Jan. 2018.

[18] S. Chakraborty, A.K. Jain and N.Mohan, "A Novel Converter Topology for Multiple Individually Regulated Outputs," in IEEE Trans. Power Electron., vol. 21, no. 2, pp. 361-369, Mar. 2006.

[19] Y. Zheng, M. Ho, J. Guo, K. L. Mak, and K. N. Leung, "A singleinductor multiple-output auto-buck-boost DC-DC converter with autophase allocation," IEEE Trans. Power Electron., vol. 31, no. 3, pp. 2296-2313, Mar. 2016.

[20] V. L. Tran, H. N. Vu, D. D. Tran, W. J. Choi, "Design and Implementation of a High-Efficiency Multiple Output Charger Based on the Time-Division Multiple Control Technique," in IEEE Trans. Power Electron., vol. 32, no. 2, pp. 1210-1219, Feb. 2017

[21] L. Hang, B. Li, S. Liu, Y. Gu, W. Yao and Z. Lu, "Asymmetrical secondary structure of LLC series resonant DC/DC converter for multioutput applications," in IET Power Electron., vol. 4, no. 9, pp. 9931001, Nov. 2011.

[22] P. Patra, J. Ghosh, and A. Patra, "Control scheme for reduced crossregulation in single-inductor multiple-output DC-DC converters," IEEE Trans. Ind. Electron., vol. 60, no. 11, pp. 5095-5104, Nov. 2013.

[23] D. Cesiel and C. Zhu, "A Closer Look at the On-Board Charger: The development of the second-generation module for the Chevrolet Volt," IEEE Electrific. Mag., vol. 5, no. 1, pp. 36-42, Mar. 2017.

[24] V. B. Vu. V. T. Doan, V. L. Pham and W. J. Choi, "A New Method to Implement the Constant Current- Constant Voltage Charge of the Inductive Power Transfer System for Electric Vehicle Applications" in Proc. ITEC, Asia-Pacific, 2016, pp. 449-453, Busan, Korea.

[25] V. B. Vu, D. H. Tran and W. J. Choi, "Implementation of the Constant Current and Constant Voltage Charge of Inductive Power Transfer Systems with the Double-Sided LCC Compensation Topology for Electric Vehicle Battery Charge Applications," IEEE Trans. Power Electron., vol. 33, no.9, pp.933-942, Sep. 2018.

[26] K. C. A. Smith and R. E. Alley, Electrical Circuit: An Introduction. Cambridge, U.K.: Cambridge Univ. Press, 1992.

[27] W. Zhang and C. C. Mi, "Compensation Topologies of High-Power Wireless Power Transfer Systems" in IEEE Trans. Veh. Technol., vol. 65, no. 6, pp. 4768 - 4778, Jul. 2015.

[28] D. Andrea "Battery Management Systems for Large Lithium-Ion Battery Packs", Artech House, 2010.

[29] R. Bosshard, J. W. Kolar, J. Mühlethaler, I. Stevanović, B. Wunsch and F. Canales, "Modeling and eta-alpha-Pareto Optimization of Inductive Power Transfer Coils for Electric Vehicles" in IEEE J. Emerg. Sel. Topic on Power Electron., vol. 3, no. 1, pp. 50-64, Mar. 2015.

[30] W. Zhang, S. C. Wong, C. K. Tse, and Q. Chen, "Load-independent duality of current and voltage outputs of a series or parallel compensated inductive power transfer converter with optimized efficiency," IEEE J. Emer. Sel. Topics Power Electron., vol. 3, no. 1, pp. 137-146, Mar. 2015.

[31] C. S. Wang, G. A. Covic and O. H. Stielau, "Power transfer capability and bifurcation phenomena of loosely coupled inductive power transfer systems," IEEE Trans. Ind. Electron., vol. 51, no. 1, pp. 148-157, Feb. 2004.

[32] Society of Automotive Engineers. (2016). Wireless power transfer for light-duty plug-in/electric vehicles and alignment methodology. [Online]. SAE Std. J2954 (unpublished). Available: http://standards.sae.org/wip/j2954/

[33] M. Fu, H. Yin, M. Liu, Y. Wang and C. Ma, "A $6.78 \mathrm{MHz}$ MultipleReceiver Wireless Power Transfer System with Constant Output Voltage and Optimum Efficiency," IEEE Trans. Power Electron., vol. 33, no. 6, pp. 5330 - 5340, Jun. 2018.

[34] H. Yin, M. Fu, M. Liu, J. Song and C. Ma,"A Autonomous Power Control in a Reconfigurable 6.78-MHz Multiple-Receiver Wireless Charging System" IEEE Trans. Ind. Electron., vol. 65, no. 8, pp. 6177 - 6187, Aug. 2018. 